\title{
Mechanistic Insight into Palladium-Catalyzed Cycloisomerization: A Combined Experimental and Theoretical Study
}

\author{
Aroonroj Mekareeya, ${ }^{\dagger}$ P. Ross Walker, ${ }^{\dagger}$ Almudena Couce-Rios, ${ }^{\ddagger}$ Craig D. Campbell, ${ }^{\dagger}$ Alan Steven, ${ }^{\S}$ \\ Robert S. Paton, ${ }^{*}+$ and Edward A. Anderson $*{ }^{*}$ (i) \\ ${ }^{\dagger}$ Chemistry Research Laboratory, University of Oxford, 12 Mansfield Road, Oxford OX1 3TA, U.K. \\ ${ }^{\ddagger}$ Departament de Química, Universitat Autònoma de Barcelona, 08193 Cerdanyola del Vallès, Spain \\ ${ }^{\S}$ AstraZeneca Pharmaceutical Techology and Development, Charter Way, Macclesfield, Cheshire SK10 2NA, U.K.
}

\section{Supporting Information}

\begin{abstract}
The cycloisomerization of enynes catalyzed by $\mathrm{Pd}(\mathrm{OAc})_{2}$ and bis-benzylidene ethylenediamine (bbeda) is a landmark methodology in transition-metal-catalyzed cycloisomerization. However, the mechanistic pathway by which this reaction proceeds has remained unclear for several decades. Here we describe mechanistic investigations into this reaction using enynamides, which deliver azacycles with high regio- and stereocontrol. Extensive ${ }^{1} \mathrm{H}$ NMR spectroscopic studies and

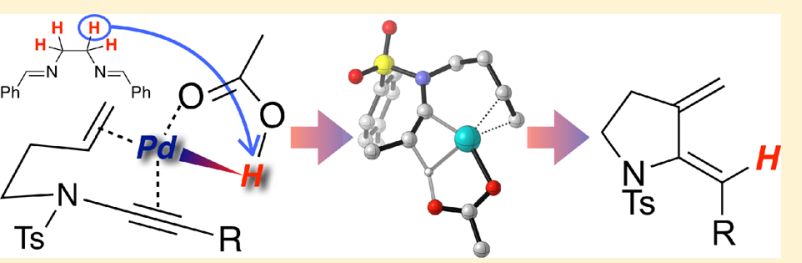
isotope effects support a palladium(II) hydride-mediated pathway and reveal crucial roles of bbeda, water, and the precise nature of the $\mathrm{Pd}(\mathrm{OAc})_{2}$ pre-catalyst. Computational studies support these mechanistic findings and lead to a clear picture of the origins of the high stereocontrol that can be achieved in this transformation, as well as suggesting a novel mechanism by which hydrometalation proceeds.
\end{abstract}

\section{INTRODUCTION}

Transition-metal-catalyzed cycloisomerizations are among the most atom-efficient methods to access organic ring systems. ${ }^{1}$ The appeal of these skeletal reorganizations lies in both the importance of ring synthesis in organic chemistry and the diversity of products that can arise from a single substrate, depending on the mechanistic pathway taken. ${ }^{1 \mathrm{a}, \mathrm{b}, 2}$ Among the many transition metals that have been used for enyne cycloisomerization, palladium catalysts have seen widespread use, with extensive work from Trost and co-workers demonstrating the versatility of this metal in three particularly robust catalyst systems (Scheme 1 , eq 1$):{ }^{3} \mathrm{Pd}(\mathrm{OAc})_{2} /$ triarylphosphine, ${ }^{4} \mathrm{Pd}(\mathrm{OAc})_{2} /$ bis-benzylidene ethylenediamine (bbeda), ${ }^{4 \mathrm{~d}, \mathrm{e}, 5}$ and $\mathrm{Pd}_{2} \mathrm{dba}_{3} \cdot \mathrm{CHCl}_{3} / \mathrm{AcOH}$ (with or without

Scheme 1. Palladium-Catalyzed Cycloisomerization of Enynes and Enynamides

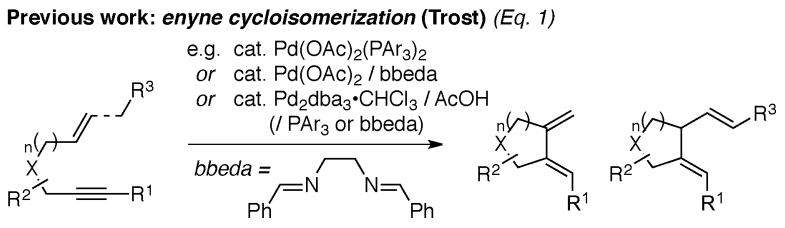

Our work: enynamide cycloisomerization (Eq. 2)

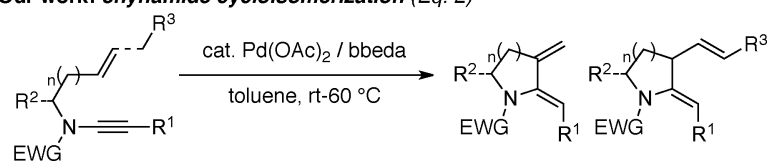

phosphine ligand or bbeda). ${ }^{6}$ Since these pioneering studies, palladium-catalyzed cycloisomerization has been widely exploited in methodology ${ }^{3}$ and synthesis contexts. ${ }^{4 \mathrm{~b}, 5 \mathrm{~b}, 7}$ Our group has shown that $\mathrm{Pd}(\mathrm{OAc})_{2}$ /bbeda is particularly effective in catalyzing the cycloisomerization of enynamides to pyrrolidine and piperidine enamides (Scheme 1, eq 2), ${ }^{8}$ useful heterocycles that can undergo a variety of further ring-forming transformations. ${ }^{9}$

Despite this rich history, the mechanism by which the $\mathrm{Pd}(\mathrm{OAc})_{2} /$ bbeda catalyst system operates is far from clear. Under $\mathrm{Pd}_{2} \mathrm{dba}_{3}$ catalysis, it is widely accepted that reaction of $\operatorname{Pd}(0)$ with acetic acid generates a palladium(II) hydride species (Scheme 2, Path A), which effects cycloisomerization by alkyne hydropalladation $(1 \rightarrow 2)$, alkene carbopalladation (3), and $\beta$ hydride elimination. This latter process, which regenerates palladium(II) hydride, can give rise to three isomeric products: a 1,3-diene and (E)- or (Z)-1,4-dienes (4-6, respectively), depending on the hydrogen atom involved. In contrast, it is not apparent that this mechanism also operates for $\mathrm{Pd}(\mathrm{OAc})_{2} /$ bbeda, not least as there is no obvious pathway for the generation of palladium(II) hydride from these components. This in part likely contributed to early proposals ${ }^{4 \mathrm{~d}, \mathrm{e}, 5}$ that this catalyst instead effects cycloisomerization by a $\mathrm{Pd}(\mathrm{II}) \rightarrow$ $\mathrm{Pd}(\mathrm{IV})$ oxidative coupling to form an intermediate palladacyclopentene 7 (Path B), ${ }^{4 \mathrm{~d}, \mathrm{sc}, 10}$ followed by $\beta$-hydride elimination (8) and then reductive elimination - a route believed to

Received: May 26, 2017

Published: July 12, 2017 
Scheme 2. Mechanistic Dichotomy for Pd-Catalyzed Enyne Cycloisomerization

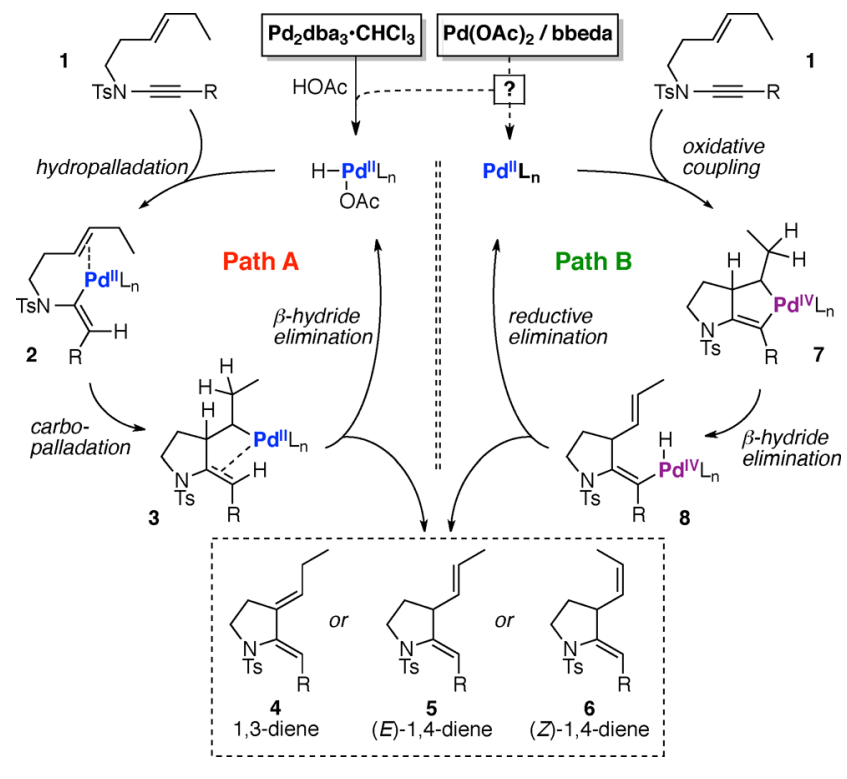

operate for other transition metals such as ruthenium and rhodium. ${ }^{1 \mathrm{~g}, 6 \mathrm{f}}$ However, despite the proposal of $\mathrm{Pd}(\mathrm{IV})$ palladacycles in other palladium-catalyzed processes, ${ }^{11}$ no direct evidence for palladacyclopentenes has been reported. Other support for this pathway includes high selectivity for $\beta$ hydride elimination "away" from the newly formed ring (leading to a 1,4-diene), which would be favored on geometric grounds as the $\mathrm{C}-\mathrm{Pd}$ and bridgehead $\mathrm{C}-\mathrm{H}$ bonds cannot easily adopt a syn-coplanar orientation in palladacycle 7 , and also through the observation of different product distributions between the various palladium catalyst systems. ${ }^{3 a, 6 e}$ In light of this continuing uncertainty, both mechanistic explanations have been routinely adopted. ${ }^{12}$

On the basis of our own experimental observations, ${ }^{8}$ we questioned whether enynamide cyclizations could offer new insight into this mechanistic puzzle, and a deeper understanding of the high stereoselectivity that can be achieved in the cyclizations. We report here studies that offer compelling evidence for palladium(II) hydride intermediacy in enynamide cycloisomerization under $\mathrm{Pd}(\mathrm{OAc})_{2}$ /bbeda catalysis, including the discovery of significant kinetic isotope effects, the influence of water and the nature of the precatalyst on the reaction pathway, and three distinct processes that depend on bbeda. Alongside this, theoretical analysis of the reaction mechanism rationalizes reaction stereoselectivity, and leads to the proposal of a new mechanism for hydropalladation.

\section{RESULTS AND DISCUSSION}

Reaction Optimization and Regio-/Stereoselectivity Observations. A screen of palladium-catalyzed enyne cycloisomerization conditions ${ }^{4-6}$ had revealed that cyclization of enynamide 1a to amidodiene $4 \mathbf{a}$ (Scheme $3 \mathrm{a}$ ) could best be effected using $\mathrm{Pd}(\mathrm{II})$ precatalysts, with $\mathrm{Pd}(\mathrm{OAc})_{2} /$ bbeda offering superior reactivity. ${ }^{8,13} \mathrm{Pd}_{2} \mathrm{dba}_{3} \cdot \mathrm{CHCl}_{3} / \mathrm{AcOH}$ systems gave poor conversion unless employed in combination with bbeda, which effected rapid conversion of 1 a to $4 a$, albeit at higher temperature. Cyclization of enynamide 1a under $\mathrm{Ru}$ catalysis $(5 \mathrm{~mol} \% \mathrm{Cp} * \mathrm{Ru}(\mathrm{cod}) \mathrm{Cl} \text { in } \mathrm{MeCN})^{14}$ provided a
Scheme 3. Regio- and Stereoselectivity in the Cyclization of Mono- and 1,2-Disubstituted Enynamides

a

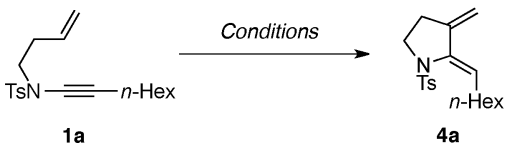

Conditions: $\mathrm{Pd}(\mathrm{OAc})_{2} /$ bbeda $(2.5 \mathrm{~mol} \%)$, toluene, $\mathrm{rt}, 20 \mathrm{~min}, 85 \%$ or $\mathrm{Pd}_{2} \mathrm{dba}_{3} \cdot \mathrm{CHCl}_{3} / \mathrm{AcOH} /$ bbeda $\left(5 \mathrm{~mol} \%\right.$ ), toluene, $60^{\circ} \mathrm{C}$ $10 \mathrm{~min}, 53 \%$

or $\mathrm{Cp}^{*} \mathrm{Ru}(\mathrm{cod}) \mathrm{Cl}(5 \mathrm{~mol} \%), \mathrm{MeCN}, 60^{\circ} \mathrm{C}, 1.5 \mathrm{~h}, 80 \%$

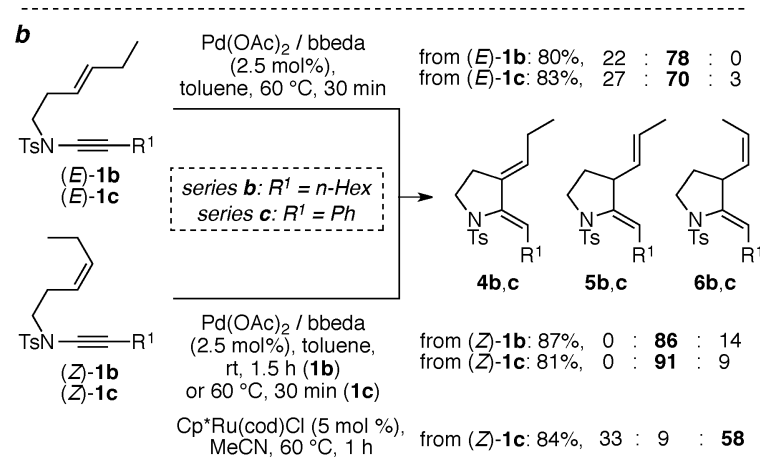

useful reference point of a reaction widely recognized to proceed through a metallacycle intermediate. ${ }^{\mathrm{g}, 6 \mathrm{f}}$

Under the $\mathrm{Pd}(\mathrm{OAc})_{2}$ /bbeda catalytic manifold, we found that the cycloisomerization of 1,2-disubstituted alkenes occurs with high stereo- and regioselectivity: enynamides $(E)-\mathbf{1 b} / \mathbf{c}$ gave predominantly the $(E)$-1,4-dienes $\mathbf{5 b}$ and $\mathbf{5 c}$, with minor amounts of 1,3-diene and only traces of $(Z)$-1,4-diene, while reaction of enynamides $(Z)-\mathbf{1 b} / \mathbf{c}$ also afforded $\mathbf{5 b}$ and $\mathbf{5 c}$ as the major products, but now with minor amounts of $(Z)$-1,4-diene and only traces of 1,3-diene. ${ }^{15}$ The equivalent cyclization of $(Z)-1 c$ under ruthenium catalysis led to a contrasting product ratio, with $(Z)$-1,4-diene $6 \mathrm{c}$ being the major product. As this latter cyclization likely proceeds through a ruthenacycle intermediate, ${ }^{16}$ this differing selectivity already seemed suggestive of distinct mechanistic pathways.

We also observed very high levels of substrate stereocontrol in cycloisomerizations that generate new stereocenters (Table 1). Entry 1 shows the influence of a substituent adjacent to the ynamide nitrogen atom, which gave a single regio- and stereoisomer of pyrrolidine enamide $5 \mathrm{~d}$. The formation of trisubstituted piperidine enamide 5e (Entry 2) proceeded with equivalent stereoselectivity, but reduced regioselectivity, with small amounts of 1,3- and 1,5-diene produced alongside the (E)-1,4-diene 5e. The formation of a 1,5-diene may reflect a reversible $\beta$-hydride elimination in the final step of the catalytic pathway, as is often seen in Heck reactions. A disubstituted enynamide tether also led to exceptional stereocontrol in the formation of tetrasubstituted pyrrolidine $5 \mathbf{f}$ (Entry 3$).{ }^{17}$ Entries 4 and 5 depict cyclizations that generate quaternary stereocenters with remarkable stereocontrol, with pyrrolidines $\mathbf{5 g}$ and $\mathbf{5 h}$ formed as single isomers. The exquisite stereoselectivity imparted in these cyclizations can be rationalized by a theoretical analysis of the reaction pathway (see below), in which the irreversible cyclization step operates with very high levels of stereocontrol.

Deuterium Crossover Experiments $/{ }^{1} \mathrm{H}$ NMR Spectroscopic Reaction Profiling. Deuterium crossover experiments could offer insight as to whether an inter- or intramolecular hydride transfer takes place; the former would suggest involvement of a discrete palladium hydride species, while the 
Table 1. Diastereoselective Cycloisomerizations of Enynamides with Substituted Tethers ${ }^{a}$

Entry Substrate

${ }^{a}$ Reaction conditions: $5 \mathrm{~mol} \% \mathrm{Pd}(\mathrm{OAc})_{2}, 5$ mol\% bbeda, toluene $(0.167 \mathrm{M}), 60{ }^{\circ} \mathrm{C}, 30 \mathrm{~min}$; entry 2 reaction time $=90 \mathrm{~min} .{ }^{b}$ Isolated yield. ${ }^{c}$ Ratio of 1,3-:1,4-:1,5-dienes as determined by ${ }^{1} \mathrm{H}$ NMR spectroscopic analysis of the crude reaction mixture.

latter would be more consistent with a metallacycle pathway. To explore this, deuterated toluenesulfonyl enynamide D-1a $(>98 \% \text { D) })^{18}$ and non-deuterated $p$-nitrobenzenesulfonyl enynamide $1 \mathrm{i}$ were reacted in a 1:1 ratio using each of the catalyst systems (Scheme 4). With $\mathrm{Pd}_{2} \mathrm{dba}_{3} \cdot \mathrm{CHCl}_{3} / \mathrm{AcOH} /$ bbeda,

Scheme 4. Deuterium Crossover Experiments

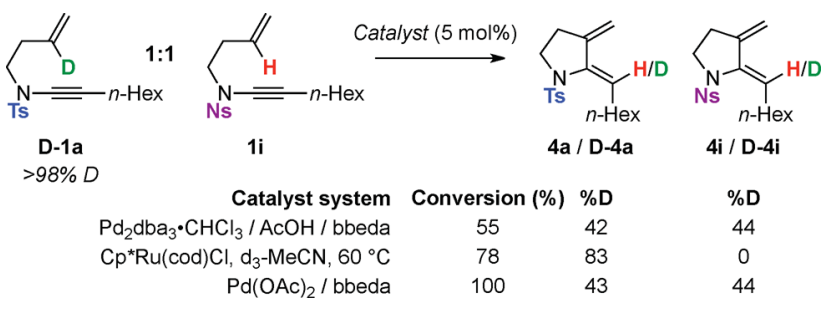

complete crossover of the deuterium label was observed. In contrast, under ruthenium catalysis, no crossover occurred and D-4a was isolated with $83 \% \mathrm{D}$ incorporation (supporting an intramolecular hydride transfer pathway). Finally, products 4 a and $4 \mathbf{i}$ arising from the equivalent $\mathrm{Pd}(\mathrm{OAc})_{2}$ /bbeda experiment also featured nearly equivalent amounts of deuterium incorporation (43 and $44 \%$ respectively), thus supporting intermolecular transfer of hydride via a discrete $\mathrm{Pd}-\mathrm{H} / \mathrm{D}$ intermediate under both palladium-catalyzed reaction conditions.

To compare the three reaction manifolds in more detail, we next monitored the cyclizations of 1a using ${ }^{1} \mathrm{H}$ NMR spectroscopy. Under $\mathrm{Pd}_{2} \mathrm{dba}_{3} \cdot \mathrm{CHCl}_{3} / \mathrm{AcOH} /$ bbeda or $\mathrm{Cp} * \mathrm{Ru}$ (cod) $\mathrm{Cl}$ catalysis (Figure 1, graphs a and b), immediate conversion of starting material to product was observed, sugggesting that a catalytically competent species is present, or rapidly formed, at the start of the reaction. ${ }^{19}$ In the case of $\mathrm{Pd}_{2} \mathrm{dba}_{3} \cdot \mathrm{CHCl}_{3}$, this is presumably a palladium(II) hydride

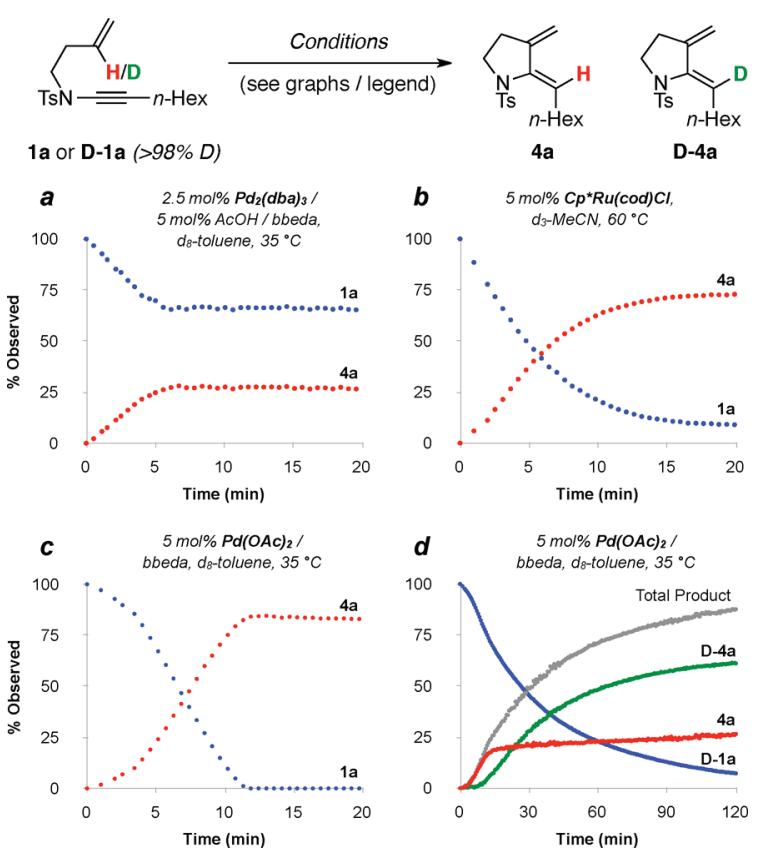

Figure 1. ${ }^{1} \mathrm{H}$ NMR spectroscopic profiles of reaction of enynamide 1a, and deuterated enynamide D-1a. Graphs a-c show the conversion of 1a (blue) to 4a (red); reaction conditions are indicated. Graph d shows the conversion of D-1a (blue) to $\mathbf{4 a}$ (red) and D-4a (green); total product formation is shown in gray. ${ }^{21}$

species, formed through oxidative addition of $\mathrm{Pd}(0)$ with acetic acid; $^{3 b, 6,20}$ whereas the ruthenium-catalyzed reaction likely only requires ligand exchange of cyclooctadiene and the substrate in the $\mathrm{Cp} * \mathrm{Ru}(\mathrm{I})(\mathrm{L})_{2}$ complex. A marked difference in reaction profile was observed with $\mathrm{Pd}(\mathrm{OAc})_{2} /$ bbeda (graph c): despite this being a superior catalyst system (compared to the other catalysts) in terms of conversion and scope, this reaction exhibited a distinct induction period that presumably relates to the generation of an active catalyst species from $\mathrm{Pd}(\mathrm{OAc})_{2}$. The conversion of $\mathbf{D}-1 \mathbf{a}$ to the deuterated product $\mathrm{D}-\mathbf{4 a}$ was also monitored (graph $\mathrm{d}$ ): this reaction required a much extended reaction time to reach full conversion compared with nondeuterated1a, revealing significant deuterium isotope effects (vide infra). Of greater intrigue was the observation that the extent of product deuteration changed during the reaction. At early stages, only protiated product was produced (red curve), whereas at later stages, the deuterated product was formed almost exclusively (green curve) - in this case leading to a drop of deuterium incorporation from $100 \% \mathrm{D}$ in the starting material D-1a, to $\sim 70 \%$ in the product D-4a.

This result led us to speculate that water has a crucial impact on reaction progress and product formation, with deuterium loss arising from an exchange process with water present in the NMR reaction solvent. We therefore set about comparing the reaction profiles of $1 \mathbf{a}$ and $\mathbf{D}$-1a using $d_{8}$-toluene containing varying concentrations of water (determined by Karl Fischer titration); the results of these collected experiments are illustrated in Figure 2. Non-deuterated 1a was first tested using pre-dried $d_{8}$-toluene as solvent (dried for several days over $4 \AA$ molecular sieves, $\left.3 \mathrm{ppm} \mathrm{H}_{2} \mathrm{O}\right){ }^{22}$ We found that a somewhat extended reaction time was required to reach completion (Figure 2, graph HA) compared to the reaction using "bottle" $d_{8}$-toluene ( $82 \mathrm{ppm}$ of $\mathrm{H}_{2} \mathrm{O}$, graph $\mathrm{HB}$ ), indicating a beneficial effect of water on reaction rate. This trend extended to water-saturated $d_{8}$-toluene (480 ppm, graph 

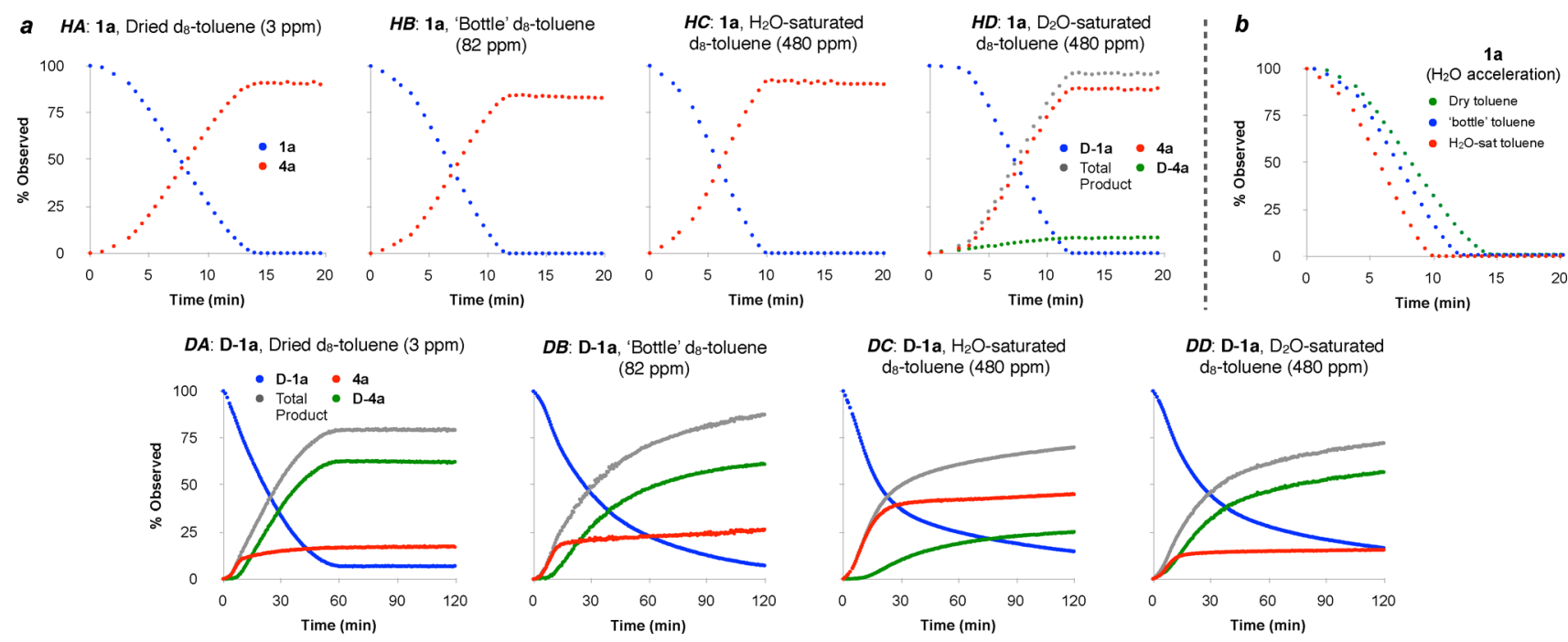

Figure 2. (a) ${ }^{1} \mathrm{H}$ NMR spectroscopic reaction profiles of 1a (graphs HA-HD) and D-1a (graphs DA-DD) using dry, bottle, and $\mathrm{H}_{2} \mathrm{O}-$ or $\mathrm{D}_{2} \mathrm{O}$ saturated $d_{8}$-toluene as reaction solvent. Graphs HA-HD show the conversion of 1a (blue) to $4 \mathbf{a}$ (red) and D-4a (green). Graphs DA-DD shows the conversion of D-1a (blue) to $\mathbf{4 a}$ (red) and D-4a (green); total product formation is shown in gray. (b) Comparison of increasing water content on reaction of enynamide 1a. ${ }^{21}$ All reactions run at $35^{\circ} \mathrm{C}, 0.167 \mathrm{M}$ in substrate, using $5 \mathrm{~mol} \% \mathrm{Pd}(\mathrm{OAc})_{2} / \mathrm{bbeda}$.

HC), where a further acceleration was observed; a summary of this effect is illustrated in Figure 2b. Interestingly, running the reaction in $d_{8}$-toluene saturated with $\mathrm{D}_{2} \mathrm{O}$ led to the incorporation of a small amount of deuterium into the product (graph HD), thus confirming that adventitious water can indeed serve as a source of "hydride". The equivalent reactions of the deuterated substrate D-1a (graphs DA-DD) showed that as the water $\left(\mathrm{H}_{2} \mathrm{O}\right)$ content of the reaction solvent increases, so does the proportion of protiated product $\mathbf{4 a}$ (red curves in graphs DA-DC), which is consistently and exclusively produced at the start of all reactions. Notably, around $15 \%$ of protiated product was produced in both reactions DA and DD, despite the use of $100 \%$ deuterated substrate and a reaction medium devoid of $\mathrm{H}_{2} \mathrm{O}$. This observation was later to be rationalized through discovery of the pathway for reaction initiation. ${ }^{23}$

The Role of Water. We hypothesized that water could accelerate the reaction through involvement in the initiation process. Bedford et al. ${ }^{24}$ recently characterized the influence of water on $\mathrm{Pd}(\mathrm{OAc})_{2}$, which in organic solutions exists as a trimeric complex $\left[\mathrm{Pd}_{3}(\mathrm{OAc})_{6}\right]$, a structure with $D_{3 h}$ symmetry featuring bridging acetate ligands. ${ }^{25}$ In the presence of water, this trimer is in equilibrium with the $\left[\mathrm{Pd}_{3}(\mathrm{OAc})_{5} \mathrm{OH}\right]$ (Figure $3 \mathrm{a})$, in which one of the bridging acetate ligands has been
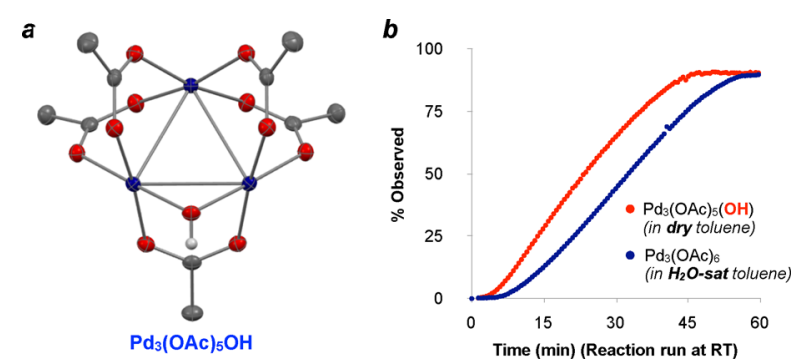

Figure 3. Effects of water on the cycloisomerization of 1a to 4a (product formation shown). (a) Structure of $\left[\mathrm{Pd}_{3}(\mathrm{OAc})_{5} \mathrm{OH}\right]{ }^{25 \mathrm{~b}}$ (b) $\left[\mathrm{Pd}_{3}(\mathrm{OAc})_{5} \mathrm{OH}\right] /$ bbeda in dried $d_{8}$-toluene (red) and $\left[\mathrm{Pd}_{3}(\mathrm{OAc})_{6}\right] /$ bbeda in $\mathrm{H}_{2} \mathrm{O}$-saturated $d_{8}$-toluene (blue). Reactions carried out with $5 \mathrm{~mol} \%[\mathrm{Pd}] /$ bbeda at room temperature. replaced by a bridging hydroxide ion. ${ }^{24}$ In increasingly waterrich environments, a greater proportion of this complex is formed, and we questioned whether this could act as a more reactive pre-catalyst. To test this, $\left[\mathrm{Pd}_{3}(\mathrm{OAc})_{5} \mathrm{OH}\right]$ was prepared as reported by Bedford. ${ }^{24}$ Reaction of $\mathbf{1 a}$ with $\left[\mathrm{Pd}_{3}(\mathrm{OAc})_{5} \mathrm{OH}\right] /$ bbeda in pre-dried $d_{8}$-toluene indeed showed a reduced induction period (Figure $3 \mathrm{a}$, red curve), compared to $\left[\mathrm{Pd}_{3}(\mathrm{OAc})_{6}\right] /$ bbeda in $\mathrm{H}_{2} \mathrm{O}$-saturated $d_{8}$-toluene (blue curve), suggesting that hydrolysis of $\left[\mathrm{Pd}_{3}(\mathrm{OAc})_{6}\right]$ is an important process in reaction initiation. Interestingly, the post-initiation rate of these reactions was similar, which may imply that a common catalytic species forms from both pre-catalysts.

The Role of bbeda. Although $\mathrm{Pd}(\mathrm{OAc})_{2}$-catalyzed cycloisomerizations can operate in the absence of bbeda, reactions in which it is present reach completion more rapidly. ${ }^{1} \mathrm{H}$ NMR spectroscopic reaction profiles for the cycloisomerization of $\mathbf{1 a}$ showed that bbeda-free reactions fail to reach completion after $>3 \mathrm{~h}$ (Figure 4, red curve), compared to $\sim 15 \mathrm{~min}$ in its presence (blue curve). The appearance of these reactions also differs markedly: in the absence of bbeda, black particulates develop over time, as opposed to a consistent yellow color (and

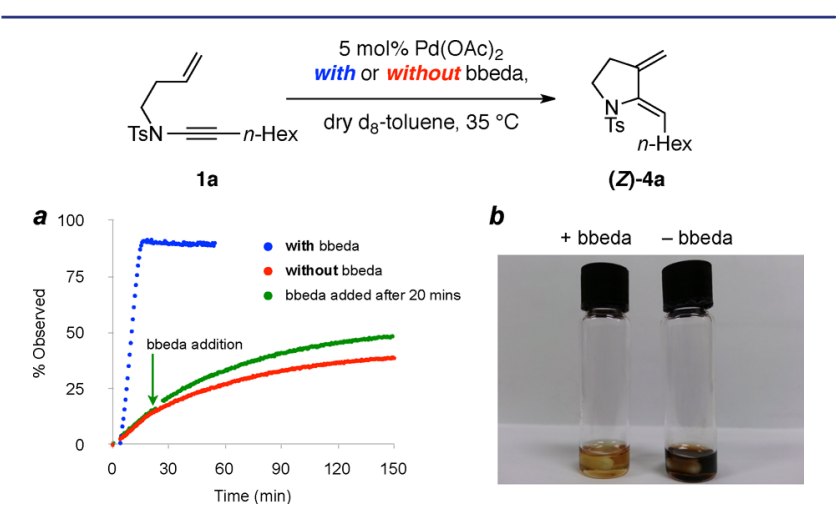

Figure 4. Influence of bbeda on the cycloisomerization of 1a. (a) Reaction profile in the presence (blue) and absence (red) of bbeda; and a delayed bbeda addition (green). (b) Visual comparison of bbeda-promoted and bbeda-free reactions. 
little or no particulate formation) in reactions containing the imine. Possible roles of bbeda include that of a ligand which accelerates the catalytic cycle, ${ }^{7 f}$ or a stabilizing component for off-cycle palladium species. Interestingly, addition of bbeda after 20 min reaction time to a bbeda-free reaction did not lead to a marked acceleration (Figure 4, green curve) but did result in a somewhat higher rate of reaction being sustained compared to the bbeda-free reaction. Although these two reactions may well operate by different pathways, this could indicate that bbeda inhibits catalyst aggregation.

From these experiments, it also seemed possible that bbeda might also be involved in precatalyst deaggregation and/or reaction initiation. To explore this, we titrated solutions of $\left[\mathrm{Pd}_{3}(\mathrm{OAc})_{5}(\mathrm{OH})\right]$ and $\left[\mathrm{Pd}_{3}(\mathrm{OAc})_{6}\right]$ in anhydrous $d_{8}$-toluene with bbeda (Figure 5). A dramatic effect was seen on addition

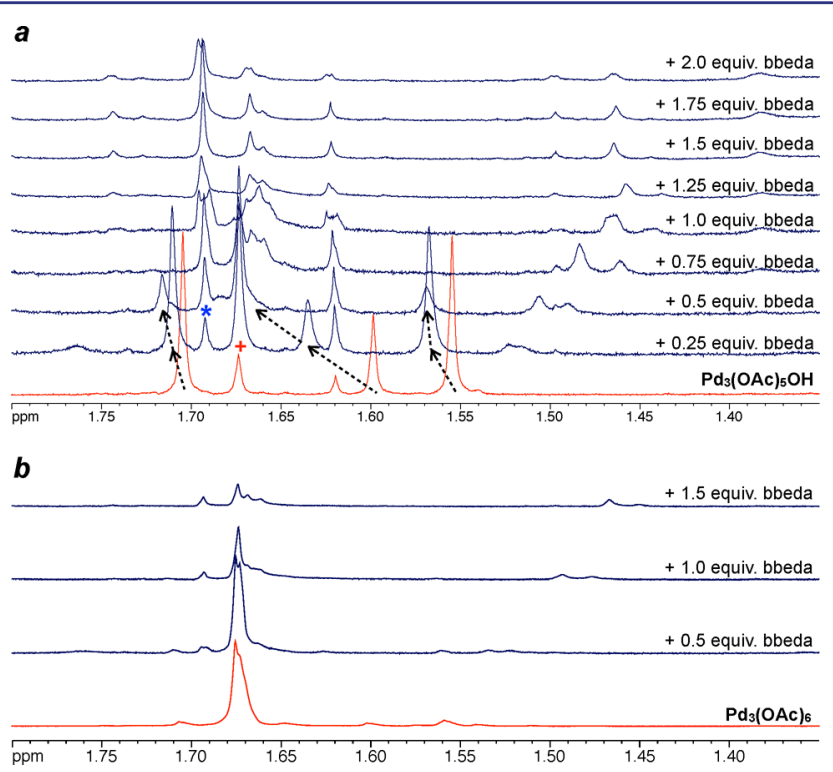

Figure 5. Effect of bbeda on (a) $\left[\mathrm{Pd}_{3}(\mathrm{OAc})_{5} \mathrm{OH}\right]$ and (b) $\left[\mathrm{Pd}_{3}(\mathrm{OAc})_{6}\right]$. Titrations performed in dry $d_{8}$-toluene at room temperature.

of even 0.25 equiv of bbeda to $\left[\mathrm{Pd}_{3}(\mathrm{OAc})_{5}(\mathrm{OH})\right]$ (titration a): the ${ }^{1} \mathrm{H}$ NMR signals corresponding to this complex at $\delta_{\mathrm{H}} 1.70$, 1.60 , and $1.55 \mathrm{ppm}$ shifted downfield (dashed arrows), and a significant new signal appeared at $1.69 \mathrm{ppm}(*)$. The proportion of $\left[\mathrm{Pd}_{3}(\mathrm{OAc})_{6}\right](+, 1.67 \mathrm{ppm})$ appeared to increase; with addition of further bbeda, this peak was consumed. Under these conditions, it thus seems that these two complexes are in facile equilibrium, and that $\left[\mathrm{Pd}_{3}(\mathrm{OAc})_{5}(\mathrm{OH})\right]$ is converted by bbeda to an unidentified species, which we suggest to be a deaggregated complex. In contrast, a solution of pure $\left[\mathrm{Pd}_{3}(\mathrm{OAc})_{6}\right]$ was barely affected by bbeda until 1.0-1.5 equiv of ligand was added (titration $b$ ). The greater susceptibility of $\left[\mathrm{Pd}_{3}(\mathrm{OAc})_{5}(\mathrm{OH})\right]$ to the action of bbeda may explain the decreased induction period observed when using this complex, or $\left[\mathrm{Pd}_{3}(\mathrm{OAc})_{6}\right]$ in water-rich reactions (see Figure 3); however, the dramatically enhanced rate of reactions run in the presence of bbeda (Figure 4) yet remained unexplained.

Initiation Pathway. Although we had now identified a number of different factors that influenced the rate of initiation, the source of the putative palladium(II) hydride remained a mystery, particularly given the consistent low levels of protiated product observed under anhydrous/protium-free reactions of
D-1a (graphs DA and DD, Figure 2). The reactions of a number of other substrates deuterated at various positions did not lead to any deuteration of the enamide alkene, suggesting the substrate is not the origin of hydride. This left bbeda itself-and a key observation of the production of small amounts of benzaldehyde at early stages of our NMR experiments. $^{26}$ This aldehyde could arise from Lewis acid (i.e., $\mathrm{Pd}(\mathrm{II})$ ) promoted hydrolysis of bbeda by water in the reaction solvent, a process that would release a primary amine (9, Figure 6a), which could then undergo $\beta$-hydride elimination

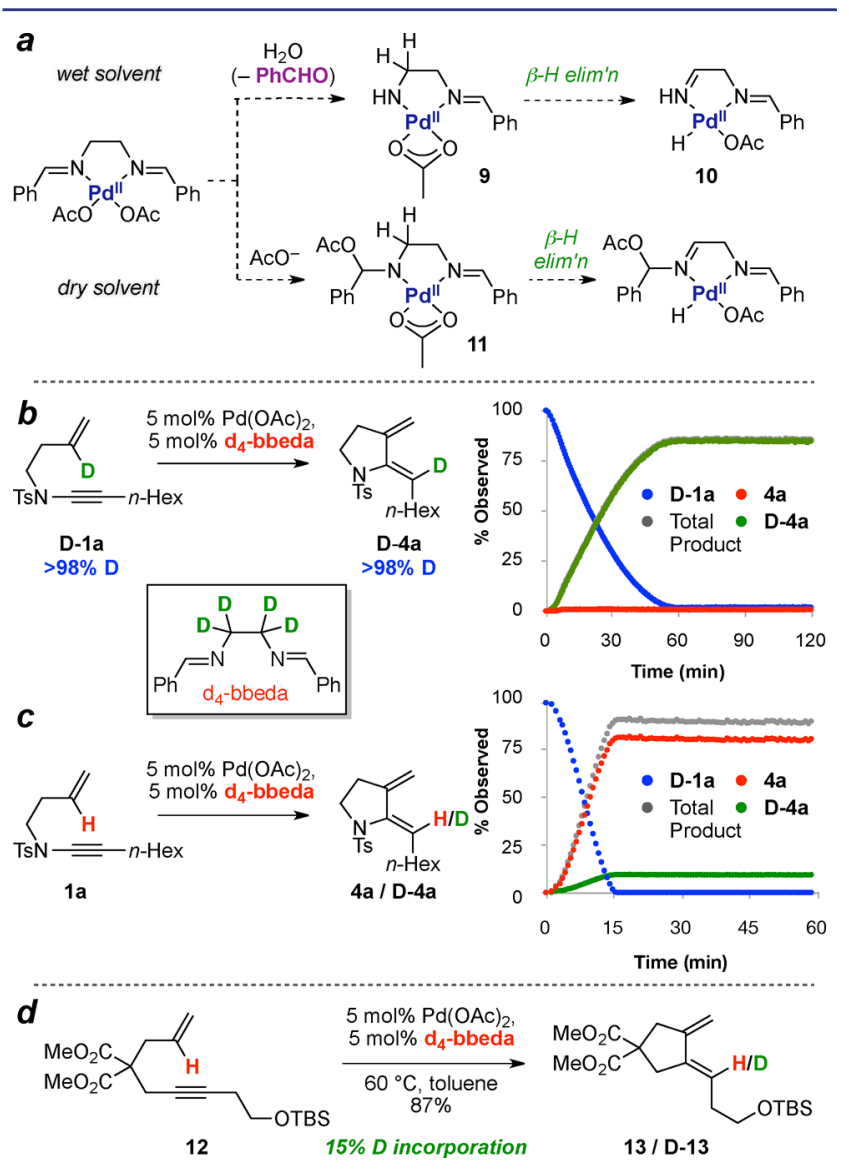

Figure 6. Bbeda as a source of hydride. (a) Proposed mechanism for the formation of $\mathrm{Pd}(\mathrm{II})-\mathrm{H}$ from bbeda. (b) Use of $d_{4}$-bbeda leads to complete deuteration of D-4a from D-1a. (c) Use of $d_{4}$-bbeda leads to partial deuteration of $4 \mathrm{a}$ from $1 \mathrm{a}^{21}$ (d) Use of $d_{4}$-bbeda with enyne 12 also leads to partial deuteration of $\mathbf{1 3}$.

to generate palladium(II) hydride. Tautomerization of the resulting imine $\mathbf{1 0}$ to the corresponding enamine could then release further hydrogen atoms. For water-free reactions (where only traces of benzaldehyde were observed), nucleophilic activation via addition of acetate to $\mathrm{Pd}(\mathrm{II})$-complexed bbeda could lead to an aminal (11) that could also be susceptible to $\beta$ hydride elimination.

To test this, $d_{4}$-bbeda was prepared by reaction of $d_{4}$ ethylenediamine with benzaldehyde. ${ }^{18}$ To our delight, cycloisomerization of D-1a in dry toluene using $d_{4}$-bbeda afforded D-4a with $>98 \%$ deuteration (Figure $6 \mathrm{~b}$ ), thus supporting the proposal that bbeda itself is the source of hydride in the initiation pathway, and explaining the formation of protiated product in experiments using D-4a and $h_{4}$-bbeda. Furthermore, reaction of the protiated substrate $1 \mathrm{a}$ in dry toluene with $d_{4}$-bbeda $(5 \mathrm{~mol}$ $\%)$ led to a low level of product deuteration $(15 \%)$, 
reinforcing this hypothesis (Figure 6c). Equally importantly, we also observed deuterium incorporation (15\%) using enyne 12 ( $87 \%$ yield), thus supporting this process as a general mechanism for initiation of enyne cycloisomerization using $\mathrm{Pd}(\mathrm{OAc})_{2}$ /bbeda (Figure 6d).

Batch Dependency. During these investigations, we also uncovered a critical dependence of the stereochemical outcome of the reaction on the batch of $\mathrm{Pd}(\mathrm{OAc})_{2}$ employed as catalyst. This discovery was made through the chance purchase of $\mathrm{Pd}(\mathrm{OAc})_{2}$ from a different supplier, which led to an unexpected ratio of enamide alkene geometries $((Z):(E)-4 a=80: 20)$, rather than the typical ratio of $\sim 97: 3$. Screening of further samples of $\mathrm{Pd}(\mathrm{OAc})_{2}$ gave variable results, the most extreme being a reversal of stereoselectivity to 40:60 in favor of the $(E)$ isomer. This batch-dependency was soon explained upon acquisition of ${ }^{1} \mathrm{H}$ NMR spectra of the various catalysts: while our original bottle of $\mathrm{Pd}(\mathrm{OAc})_{2}$ exhibited a ${ }^{1} \mathrm{H}$ NMR spectrum (in $\mathrm{CDCl}_{3}$ ) characteristic of pure $\mathrm{Pd}(\mathrm{OAc})_{2}$ (Figure 7, batch 1,
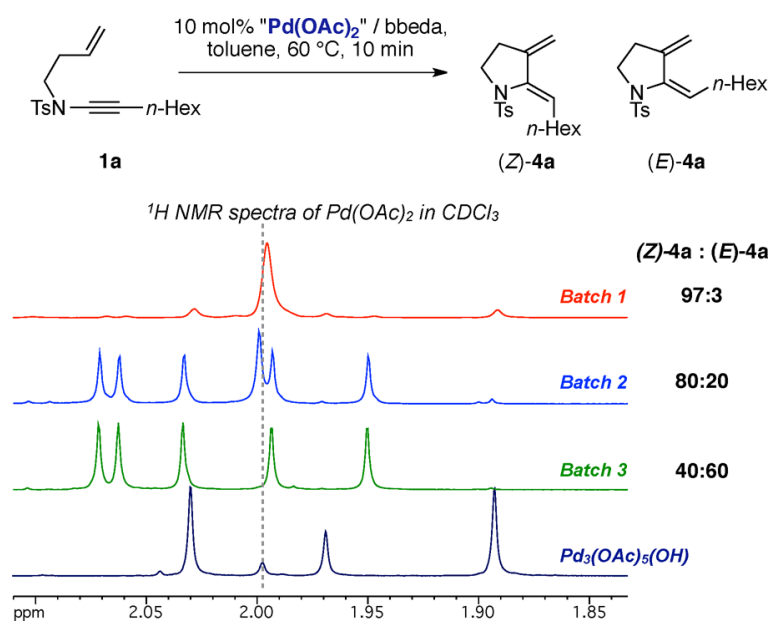

Figure 7. ${ }^{1} \mathrm{H}$ NMR spectra $\left(\mathrm{CDCl}_{3}\right)$ of batches of $\mathrm{Pd}(\mathrm{OAc})_{2}$, and batch-dependent product ratios for cycloisomerization of $\mathbf{1 a}$.

a singlet corresponding to the $D_{3 h}$-symmetric $\left[\mathrm{Pd}_{3}(\mathrm{OAc})_{6}\right]$ trimer, minor peaks arise from $\left.\left[\mathrm{Pd}_{3}(\mathrm{OAc})_{5} \mathrm{OH}\right]\right)$, ${ }^{25 a}$ other samples showed increasing amounts of an impurity (batches 2 and 3), with the worst product ratio arising from samples devoid of $\left[\mathrm{Pd}_{3}(\mathrm{OAc})_{6}\right]$. This latter batch in fact consisted solely of $\left[\mathrm{Pd}_{3}(\mathrm{OAc})_{5}\left(\mathrm{NO}_{2}\right)\right]$, an impurity common in $\mathrm{Pd}(\mathrm{OAc})_{2}$ that arises from its method of production, as previously characterized by Cotton and Murillo. ${ }^{25 a, 28}$ The ability of this "impurity" to mediate palladium-catalyzed reactions has been documented, albeit in many cases its presence does not affect the reaction outcome; ${ }^{29}$ the observation of such a significant overturning of product selection is, to our knowledge, unprecedented. The synthesis of pure $\mathrm{Pd}(\mathrm{OAc})_{2}$ from $\mathrm{Pd}\left(\mathrm{NO}_{3}\right)_{2}$ and $\mathrm{NaOAc}$ as reported by Stolyarov and coworkers $^{28}$ offers a convenient solution to this problem, and delivers palladium(II) acetate of purity equivalent to the original supply; ${ }^{1} \mathrm{H}$ NMR spectroscopic analysis of subsequent commercial batches of $\mathrm{Pd}(\mathrm{OAc})_{2}$ gave reassurance that these would behave as expected. Interestingly, monitoring of the reaction of $\mathbf{1 a}$ with $\left[\mathrm{Pd}_{3}(\mathrm{OAc})_{5}\left(\mathrm{NO}_{2}\right)\right] /$ bbeda (Figure 8) revealed that reactions with this catalyst proceeded at a somewhat lower rate than pure $\mathrm{Pd}(\mathrm{OAc})_{2}$ /bbeda, and that the isomeric ratio of enamide products remained consistent throughout the reaction. Submission of pure $(Z)-4 a$ to this
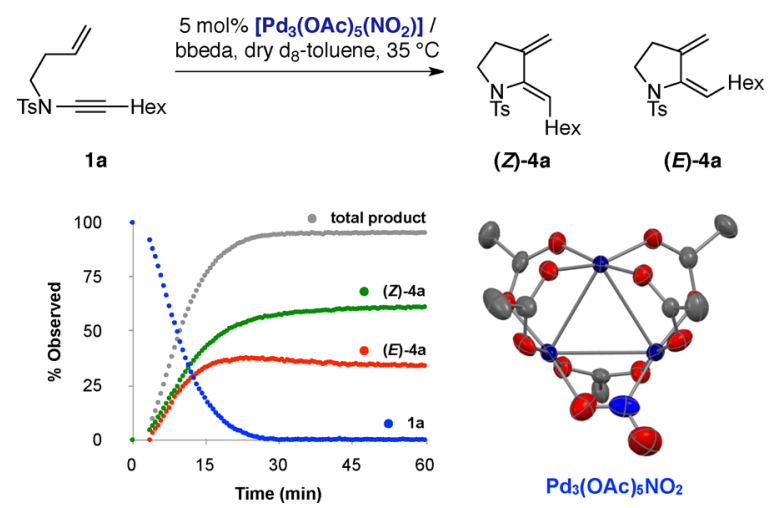

(Z)-4a

$(E)-4 a$

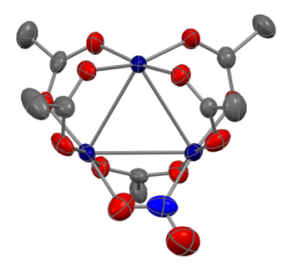

$\mathrm{Pd}_{3}(\mathrm{OAc})_{5} \mathrm{NO}_{2}$

Figure 8. ${ }^{1} \mathrm{H}$ NMR spectroscopic reaction profile for conversion of $1 \mathrm{a}$ to $(Z)-4 a$ and $(E)$-4a catalyzed by $\left.\left[\mathrm{Pd}_{3}(\mathrm{OAc})_{5}\right)\left(\mathrm{NO}_{2}\right)\right] /$ bbeda, in predried $d_{8}$-toluene at $35{ }^{\circ} \mathrm{C}$, and $\mathrm{X}$-ray crystal structure of $\mathrm{Pd}_{3}(\mathrm{OAc})_{5} \mathrm{NO}_{2}{ }^{25 \mathrm{a}}$

catalyst did not result in alkene isomerization, suggesting that the two isomers arise during the cycloisomerization as a consequence of a divergent reaction mechanism, rather than through product isomerization. While the mechanistic origin of this isomer mixture remains unknown, recent studies on alkyne semireduction using $\mathrm{Pd}\left(\mathrm{PEt}_{3}\right)_{4}$ and formic acid suggest that isomerization of alkenylpalladium complexes formed through hydropalladation can be facile. ${ }^{30}$

Computational Analysis of the Reaction Pathway. With significant experiemental evidence for the intermediacy of palladium(II) hydride species in hand, we set out to explore the reaction pathway from a theoretical perspective to establish whether a hydropalladation reaction mechanism would prove energetically feasible. In addition, we hoped to rationalize the stereoselectivity of the reaction, and to gain insight into the observed kinetic isotope effects. ${ }^{31}$ Density functional theory (DFT) and local coupled cluster calculations were performed with Gaussian09 rev D.01 and with Orca v4. ${ }^{32}$ The metageneralized gradient approximation (meta-GGA) TPSS exchange-correlation functional ${ }^{33}$ was used for all geometry optimizations ${ }^{34}$ with density fitting for Coulomb integrals (RI$\mathrm{J})$, a fine integration grid and the Karlsruhe def2-TZVP basis set for all elements. ${ }^{35}$ A quasi-harmonic approximation ${ }^{36}$ was used in which the treatment of vibrational entropies switches from a rigid-rotor harmonic oscillator to a free rotor at frequencies below $100 \mathrm{~cm}^{-1}$, implemented in Python. ${ }^{37}$ Dispersion effects were included by a Becke-Johnson damped D3-correction ${ }^{38}$ and solvation effects by an SMD description of toluene. ${ }^{39}$ Single point energy calculations were also performed with hybrid meta-GGA functionals (M06 and PW6B95-D3), and with the DLPNO-CCSD(T) local coupled cluster method for comparison. $^{40}$ The energy profile is qualitatively consistent across the different methods, and the RMSD between between TPSS-D3 and DLPNO-CCSD $(\mathrm{T})$ energies over the entire catalytic cycle is only $2.9 \mathrm{kcal} / \mathrm{mol}$. Computed diastereoselectivities are consistent within $1 \mathrm{kcal} \mathrm{mol}^{-1}$ across different levels (see the Supporting Information (SI) for full details). The putative catalytic cycle, involving hydropalladation, migratory insertion and $\beta$-hydride elimination steps, was obtained with a monomeric Pd-catalyst ${ }^{41}$ with a single acetate ligand, using model system $\mathbf{1 j}$ (Figure 9), which closely resembles substrate 1a with the alkyne substituent $(n-\mathrm{Hex}$ in 1a) represented by a methyl group.

Hydropalladation occurs from the $\operatorname{Pd}(0)$ acetic acid complex A. The expected palladium(II) hydride complex was found to 


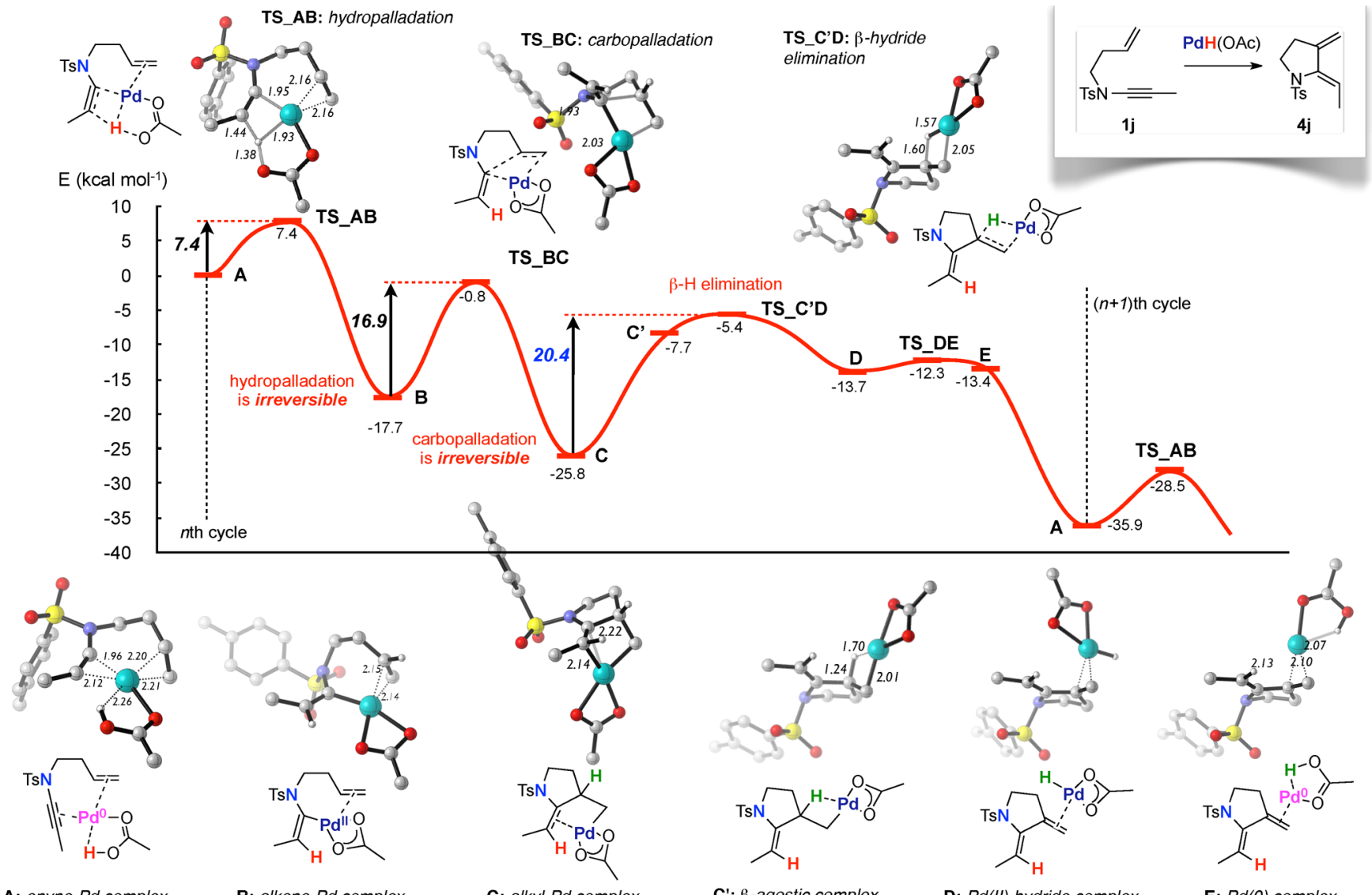

A: enyne-Pd complex

B: alkene-Pd complex

C: alkyl-Pd complex

C': $\beta$-agostic complex

D: $P d(I I)$-hydride complex

E: $\operatorname{Pd}(0)$ complex

Figure 9. SMD-TPSS-D3/def2-TZVP//TPSS/def2-TZVP energy profile for the catalytic cycle of the cycloisomerization.

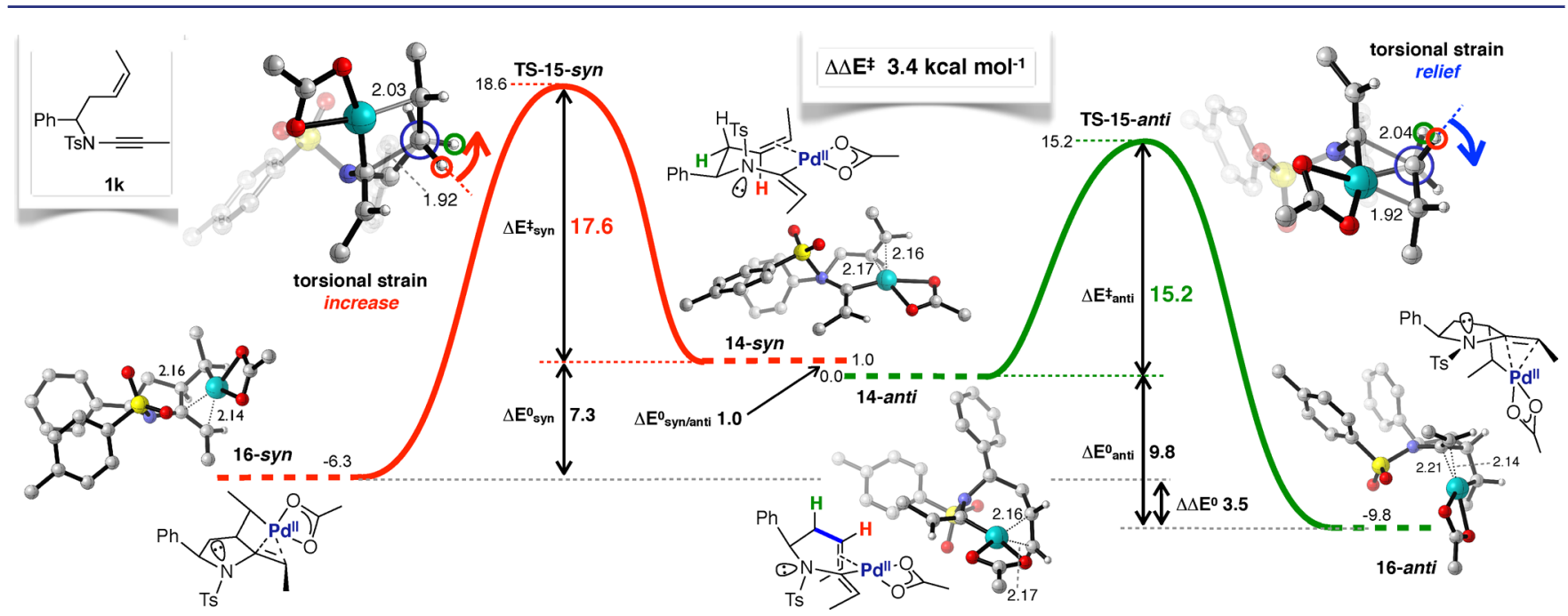

Figure 10. DFT calculations rationalize the stereochemical outcome of the anti-diastereoselective cycloisomerization of enynamide $\mathbf{1 k}$.

be significantly less stable at all levels of theory, by 21.4-33.1 $\mathrm{kcal} \mathrm{mol}^{-1} \cdot{ }^{42}$ As hydropalladation takes place to give $\mathbf{B}$, transfer of the hydrogen atom to the $\beta$-carbon of the ynamide is facilitated by an agostic interaction with the metal (TS_AB, $\Delta G^{\ddagger}=7.4 \mathrm{kcal} \mathrm{mol}^{-1}$ ), suggesting that a discrete palladium(II) hydride is not formed, or is not located as an energy minimum on the potential energy surface; in effect, oxidative addition to $\operatorname{Pd}(0)$ by acetic acid, and hydropalladation, take place as a single concerted process from the favored substrate-bound $\mathrm{Pd}(0)(\mathrm{HOAc})$ complex. As well as representing a new pathway for alkyne hydrometalation, complex $\mathbf{A}$ also accounts for the facile exchange of $\mathrm{H} / \mathrm{D}$ with water in the reaction solvent (and with hydrolyzed bbeda) which can thus be mediated by acetic acid rather than requiring a specific isotope exchange process at the metal. It also accounts for the difficulty in detecting elusive palladium(II) hydride species by ${ }^{1} \mathrm{H}$ NMR spectroscopy, and is consistent with the notion that oxidative addition of $\operatorname{Pd}(0)$ into acetic acid is rapid and reversible. ${ }^{20 b}$ Subsequent to this irreversible hydrometalation to give $\mathbf{B}$, the metal then effects carbopalladation of the alkene (TS_BC, $\Delta G^{\ddagger}=16.9 \mathrm{kcal}$ 
$\mathrm{mol}^{-1}$ ), leading to an alkylpalladium species $\mathbf{C}$ that remains complexed to the enamide alkene. Carbopalladation is also irreversible at all levels of theory considered, and is followed by rate-limiting $\beta$-hydride elimination (TS_C'D, $\Delta G^{\ddagger}=20.4 \mathrm{kcal}$ $\left.\mathrm{mol}^{-1}\right)$, a process that first requires endothermic enamide decomplexation and $\mathrm{C}-\mathrm{C}$ bond rotation in order to position the $\mathrm{C}-\mathrm{Pd}$ bond syn-coplanar with the $\mathrm{C}-\mathrm{H}$ bond $\left(\mathbf{C} \rightarrow \mathbf{C}^{\prime}\right)$. The degree of reversibility of $\beta$-hydride elimination is challenging to assess, as it depends on the kinetics of product dissociation from the resultant (alkene) $\mathrm{Pd}(\mathrm{H})(\mathrm{OAc})$ complex (D or $\mathbf{E})$, and complexation with the next molecule of substrate. This is in part likely to be product dependent, as only in certain cases is alkene isomerization observed in the product. Formation of product-bound $\mathrm{Pd}(0)$ (HOAc) complex $\mathbf{E}$ from $\mathbf{D}$ is facile, with a barrier of $2.1 \mathrm{kcal} / \mathrm{mol}$. This is true across all levels of theory, where the barrier for this step ranges from 1.7$4.2 \mathrm{kcal} / \mathrm{mol}$. In TS DE the $\kappa^{2}$-acetate rotates out of the plane to adopt a $\kappa^{1}$-coordination mode bound cis to the hydride (see the SI for full details).

The calculated energy profile of $\mathbf{1 j}$ is consistent with room temperature reactivity: ${ }^{43}$ the energetic span of the computed catalytic cycle $\left(20.4 \mathrm{kcal} \mathrm{mol}^{-1}\right)$ is commensurate with a $t_{1 / 2}$ of $3 \mathrm{~min}$. To compute the KIEs we applied the Bigeleisen-Mayer equation with a parabolic tunneling correction based on scaled TPSS/def2-TZVP harmonic frequencies at $35{ }^{\circ} \mathrm{C} .{ }^{44}$ Our calculations predict a primary KIE for $\beta$-hydride elimination of $2.225,{ }^{45}$ an inverse secondary KIE of 0.916 for carbopalladation, and a primary KIE for alkyne hydropalladation of 4.689 (12.671 with a parabolic tunneling correction). The latter value may reflect the trifurcated nature of bonding to the hydrogen atom in the hydropalladation transition state $\mathbf{T S} \mathbf{A B} .^{46}$

The stereoselectivity of the cyclization of enynamide 1e (see Table 1, entry 1 ) was next modeled using substrate $\mathbf{1 k}$ (Figure 10). The carbopalladation substrate derived from $\mathbf{1 k}$ exists in two energetically similar conformations: 14-anti and 14-syn, the diastereomeric transition states from which (TS-15-anti and TS-15-syn) lead to products anti-16 (the observed outcome) and syn-16 respectively. A free energy difference between these transition states of $\Delta \Delta G^{\ddagger}=3.4 \mathrm{kcal} \mathrm{mol}^{-1}$ corresponds to a calculated diastereoselectivity of $>180: 1{ }^{47}$ which is consistent with the observed reaction outcome. The energy difference between these transition states (consistent with M06 and DLPNO-CCSD(T), as discussed in the SI) can be rationalized by changes in torsional strain upon carbopalladation of the alkene by the alkenylpalladium complex: in the case of transition state TS-15-anti, this strain is relieved as carbopalladation proceeds (from the eclipsed C$\mathrm{H}$ bonds to red and green hydrogens in 14-anti). For the alternative transition state TS-15-syn, eclipsing interactions increase during this step (from the staggered $\mathrm{C}-\mathrm{H}$ bonds to red and green hydrogens in 14-syn). ${ }^{48}$

Experimental Observations on Isotope Effects. ${ }^{49}$ The data collected in the time course experiments indicate the influence of several isotope effects, resulting in marked differences in reaction rate and isotope incorporation as the reaction proceeds. We now turned to correlation of our computational work with these experimental observations, in particular the KIE for the rate-determining $\beta$-hydride elimination. This was achieved by comparison of the product distribution from disubstituted alkene $(E)-\mathbf{1 b}$ with that of its deuterated equivalent (E)-D-1b (Scheme 5, >98\% D, E:Z > 20:1), where $\beta$-deuteride elimination is required for the latter to
Scheme 5. Primary KIE for $\boldsymbol{\beta}$-Hydride Elimination

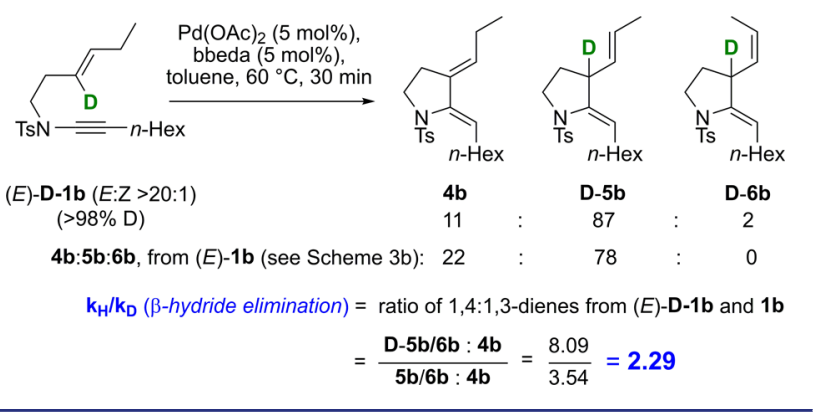

generate 1,3-diene products. The ratio of 1,3:1,4-dienes (4b: D$\mathbf{5 b} / \mathbf{D}-\mathbf{6} \mathbf{b}$, as determined by integration of appropriate peaks in the ${ }^{1} \mathrm{H}$ NMR spectrum) $)^{50}$ was found to be 8.09 , compared to a ratio of 3.54 for $(E)-\mathbf{1 b}$, which gives an experimental KIE for $\beta$ hydride elimination of 2.29. This value is consistent with other reports on $\beta$-hydride elimination from alkylpalladium complexes, and with the computed value $\left(2.07\right.$ at $60{ }^{\circ} \mathrm{C} ; 2.23$ at 35 ${ }^{\circ} \mathrm{C}$ for model substrate $\mathbf{1 j}$ ). ${ }^{45,49,51}$

While the isotope effect associated with $\beta$-hydride elimination is consistent with computation and with literature values, the overall difference in reaction rate between substrates 1a and D-1a at typical catalyst loadings of $5 \mathrm{~mol} \%$ is not explained by $\beta$-hydride elimination alone. Although negligible KIEs would be expected from the hydropalladation and carbopalladation steps, it seemed possible that off-cycle equilibrium processes might be affected by the difference in activation energies between hydro- and deuteriopalladation. The path from product decomplexation to substrate association (and subsequent irreversible hydropalladation) could involve complexation of palladium by bbeda, or its hydrolysis product, or catalyst re-aggregation (to dimeric or trimeric complexes). These processes would be expected to depend on catalyst concentration, ${ }^{52}$ with hydropalladation perturbing the equilibria by effectively sequestering monomeric "active" $\mathrm{Pd}(0)(\mathrm{AcOH})$.

This indeed turned out to be the case. The relative rates of reaction of substrates 1a and D-1a were compared at various catalyst concentrations (by observation of the post-induction regions of reactions such as $\mathrm{HA}$ and DA, see Figure 2, once the production of protiated product has plateaued in reactions involving D-1a). The rates of cyclization of each substrate were measured at five different catalyst loadings $(0.5,1,2.5,5$, and 10 mol\%, Figure 11a), with each experiment run in triplicate. The rate constants for both substrates, and their associated errors (one standard deviation) are shown in the table in Figure 11. Plateau effects were observed for both substrates at higher catalyst concentrations: ${ }^{52}$ for $1 \mathrm{a}$, this occurs at or above $5 \mathrm{~mol}$ $\%$, while for D-1a, at or above $2.5 \mathrm{~mol} \%$. We speculate this may be related to the difference in energy barriers for hydro- vs deuteriopalladation, which in the latter case could increase the extent of off-cycle catalyst sequestration, compared to substrate complexation and entry to the catalytic cycle. The dominance of hydropalladation at early reaction stages using D-1a adds support to the influence of this step on entry to the catalytic cycle. In addition, this data allowed us to determine the order of reaction with respect to the metal catalyst. A plot of $\ln \left(k_{\text {obs }}\right)$ against $\ln \left(\left[\mathrm{Pd}(\mathrm{OAc})_{2}\right]\right)$ showed a linear relationship (Figure $11 \mathrm{~b})$, supporting the proposal of a monomeric palladium species as the active catalyst. ${ }^{53}$

Alongside this, we were intrigued to observe that the rate of cycloisomerization of (Z)-D-1b exceeded that of (Z)-1b 


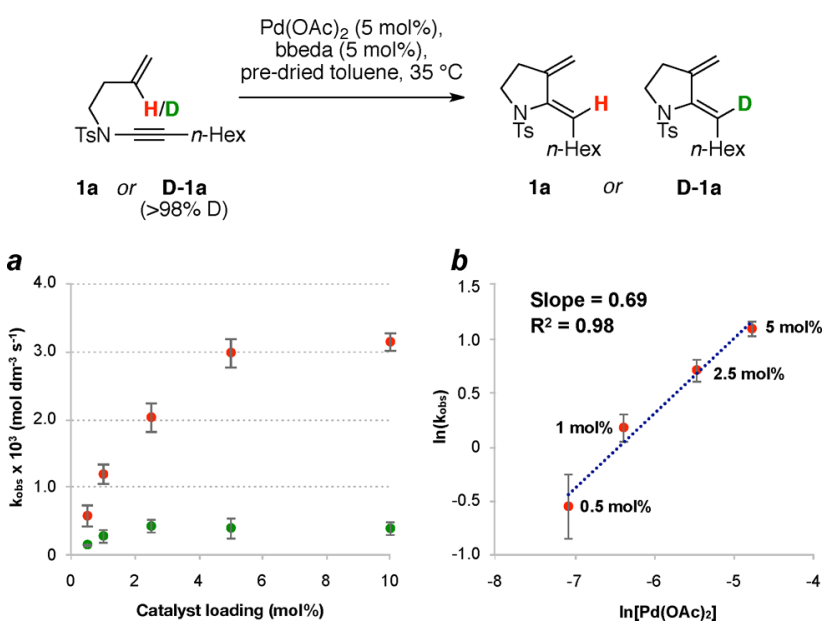

Figure 11. Dependence of reaction rate on catalyst concentration. $\mathrm{k}_{\mathrm{H}}$

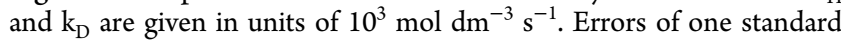
deviation are shown. (a) $k_{\mathrm{H}}$ (obs) and $k_{\mathrm{D}}$ (obs) at different catalyst concentrations; table shows values and ratios of observed rate constants. (b) Plot of $\ln \left(k_{\mathrm{H}}(\mathrm{obs})\right)$ against $\ln \left[\mathrm{Pd}(\mathrm{OAc})_{2}\right]$ shows firstorder dependence with respect to the catalyst. See the SI for further details.

(Figure 12); comparison of the steady-state regions of these reactions $(6-11 \mathrm{~min})$ gave a gradient ratio of $0.87( \pm 0.01)$.

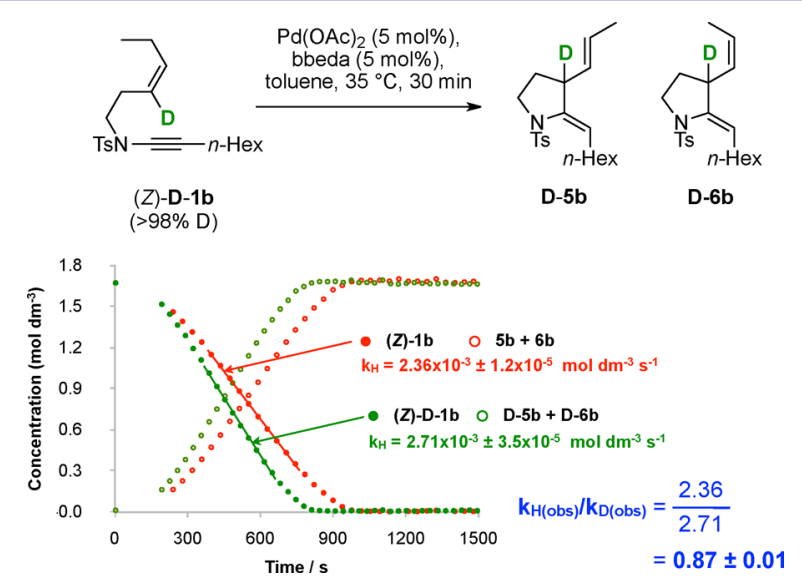

Figure 12. Isotope effect from alkene deuteration. ${ }^{21}$

The reason for this secondary KIE is not clear: with the theoretical pathway indicating carbopalladation to be non-ratedetermining, we suggest that this effect could relate to differences between the two isotopes in agostic interactions, or hyperconjugation effects during the enamide decomplexation $/ \beta$-hydride elimination steps, or during product decomplexation.

\section{DISCUSSION}

The above experimental and theoretical studies provide strong support for a hydropalladation mechanism for $\mathrm{Pd}(\mathrm{OAc})_{2} /$ bbeda-catalyzed enynamide cycloisomerization. A full outline of the proposed reaction pathway is illustrated in Scheme 6 . Reaction initiation entails a number of processes, commencing with a water-promoted $\mathrm{Pd}_{3}(\mathrm{OAc})_{6}$ equilibrium with $\left[\mathrm{Pd}_{3}(\mathrm{OAc})_{5}(\mathrm{OH})\right]$, the latter of which undergoes bbedaassisted deaggregation, presumably to give a monomeric $\left[(\right.$ bbeda $\left.) \mathrm{Pd}(\mathrm{OAc})_{2}\right]$ complex. Partial hydrolysis of this complex
Scheme 6. Pd-Catalyzed Cycloisomerization: Overview

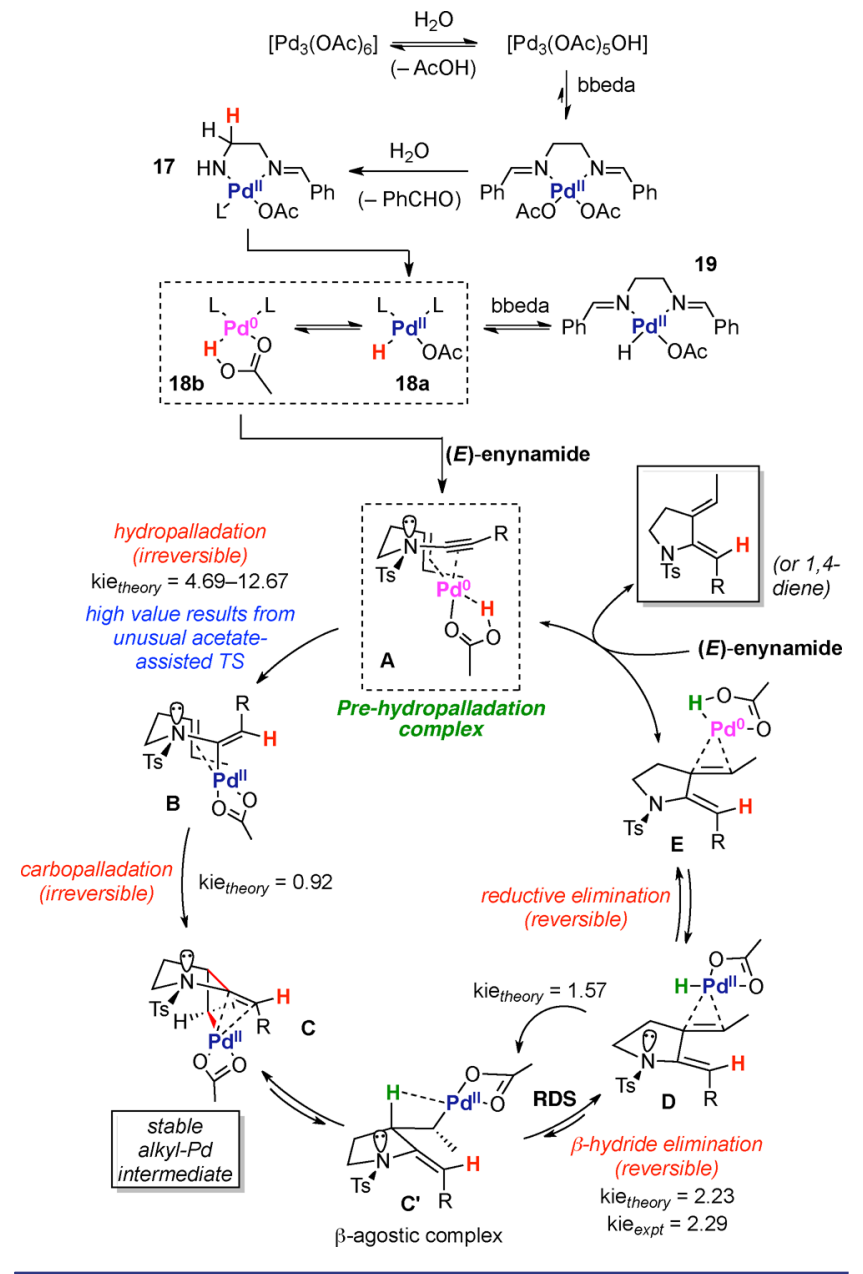

liberates benzaldehyde and amine complex 17, which undergoes $\beta$-hydride elimination to form $\mathrm{Pd}(\mathrm{II})-\mathrm{H}$ complex 18a (this process could also be promoted by addition of acetate, see Scheme 6a). Throughout the reaction, additional bbeda (or the derived amine ligand) could stabilize off cycle $\mathrm{Pd}(\mathrm{II})$ species (19), thereby prolonging catalyst lifetime. The resultant $\mathrm{L}_{2} \mathrm{Pd}(\mathrm{II}) \mathrm{H}(\mathrm{OAc})$ complex 18a is in equilibrium with $\mathrm{L}_{2} \mathrm{Pd}(0)$ $\left(\kappa^{2}-\right.$ HOAc) $18 b$, with the latter form predicted computationally to be favored on binding the enynamide substrate (A), and required for hydropalladation. ${ }^{54}$ Notably, acetic acid complex $\mathbf{1 8 b}$ also explains the facile exchange of $\mathrm{H} / \mathrm{D}$ with water. The substrate-complexed $\mathrm{Pd}(0)$ catalyst (A) then effects an irreversible "oxidative hydropalladation" of the alkyne component (to give B), followed by irreversible carbopalladation with a pseudo-axially oriented alkene group. The resulting alkylpalladium(II) species (C) offers a possible resting state of the catalyst; further reaction requires an endergonic decomplexation of the enamide from the metal, $\mathrm{C}-\mathrm{C}$ bond rotation, and agostic coordination of the bridgehead hydrogen atom $\left(\mathbf{C}^{\prime}\right) . \beta$-Hydride elimination then proceeds rapidly and potentially reversibly, delivering a $\mathrm{Pd}(\mathrm{II}) \mathrm{H}(\mathrm{OAc})$ (alkene) complex (D) that is in equilibrium with $\mathrm{Pd}(0)(\mathrm{AcOH})(\mathrm{E})$. Finally, we note that although original proposals for different reaction pathways using $\mathrm{Pd}(\mathrm{II})$ or $\mathrm{Pd}(0)$ precatalysts were based on observed differences in reaction outcomes or product distributions, we suggest that these may relate more to the influence of the specific ligand environment around the metal center, rather than the cycloisomerization pathway itself. 


\section{CONCLUSION}

Palladium-catalyzed enyne cycloisomerization is a fundamentally important reaction manifold in this field of ring synthesis. Despite the utility of the $\mathrm{Pd}(\mathrm{OAc})_{2} /$ bbeda catalyst system, mechanistic understanding has remained elusive. Through extensive NMR studies with deuterated substrates, we have uncovered the crucial influences of water, the precatalyst, and the ligand itself in this reaction. Our demonstration that bbeda itself serves as a source of $\mathrm{Pd}(\mathrm{II})-\mathrm{H}$, combined with theoretical analysis of the reaction pathway correlated with experimental isotope effects, offers a new level of understanding of this classic cyclization process, and offers enhanced understanding for the design of applications of this chemistry in stereoselective synthesis.

\section{ASSOCIATED CONTENT}

\section{S Supporting Information}

The Supporting Information is available free of charge on the ACS Publications website at DOI: 10.1021/jacs.7b05436.

Experimental details of NMR time course experiments, characterization of novel compounds, ${ }^{1} \mathrm{H}$ and ${ }^{13} \mathrm{C}$ NMR spectra, and additional experimental details (PDF)

\section{AUTHOR INFORMATION}

\section{Corresponding Authors}

*robert.paton@chem.ox.ac.uk

*edward.anderson@chem.ox.ac.uk

\section{ORCID}

Alan Steven: 0000-0002-0134-0918

Robert S. Paton: 0000-0002-0104-4166

Edward A. Anderson: 0000-0002-4149-0494

\section{Notes}

The authors declare no competing financial interest.

\section{ACKNOWLEDGMENTS}

This paper is dedicated to Prof. Barry Trost on the occasion of his 75th birthday. E.A.A. thanks the EPSRC (EP/K005391/1, $\mathrm{EP} / \mathrm{H} 025839 / 1)$ for support. R.S.P. thanks the Chemical Structure Association Trust. We acknowledge the use of the EPSRC UK National Service for Computational Chemistry Software (CHEM773) in carrying out this work. A.M. thanks the Royal Thai Government and the DPST project for a studentship. A.C.-R. is grateful to the Spanish MINECO for an FPI fellowship. We also thank Dr. John M. Brown for valuable discussions on isotope effects.

\section{REFERENCES}

(1) (a) Michelet, V.; Toullec, P. Y.; Genet, J. P. Angew. Chem., Int. Ed. 2008, 47, 4268-4315. (b) Lee, S. I.; Chatani, N. Chem. Commun. 2009, 371-384. (c) Marinetti, A.; Jullien, H.; Voituriez, A. Chem. Soc. Rev. 2012, 41, 4884-4908. (d) Watson, I. D. G.; Toste, F. D. Chem. Sci. 2012, 3, 2899-2919. (e) Dorel, R.; Echavarren, A. M. Chem. Rev. 2015, 115, 9028. (f) Furstner, A. Chem. Soc. Rev. 2009, 38, 32083221. (g) Trost, B. M.; Frederiksen, M. U.; Rudd, M. T. Angew. Chem., Int. Ed. 2005, 44, 6630-6666. (h) Zhang, L.; Sun, J.; Kozmin, S. A. Adv. Synth. Catal. 2006, 348, 2271-2296. (i) Jiménez-Núñez, E.; Echavarren, A. M. Chem. Rev. 2008, 108, 3326-3350. (j) Yamamoto, Y. Chem. Rev. 2012, 112, 4736-4769. (k) Aubert, C.; Buisine, O.; Malacria, M. Chem. Rev. 2002, 102, 813-834.

(2) (a) Lloyd-Jones, G. C. Org. Biomol. Chem. 2003, 1, 215-236. (b) Nieto-Oberhuber, C.; López, S.; Jiménez-Núñez, E.; Echavarren, A. M. Chem. - Eur. J. 2006, 12, 5916-5923.
(3) (a) Trost, B. M. Acc. Chem. Res. 1990, 23, 34-42. (b) Trost, B. M. Chem. - Eur. J. 1998, 4, 2405-2412.

(4) (a) Trost, B. M.; Lautens, M. J. Am. Chem. Soc. 1985, 107, 17811783. (b) Trost, B. M.; Chung, J. Y. L. J. Am. Chem. Soc. 1985, 107, 4586-4588. (c) Trost, B. M.; Lautens, M. Tetrahedron Lett. 1985, 26, 4887-4890. (d) Trost, B. M.; Lautens, M.; Chan, C.; Jebaratnam, D. J.; Mueller, T. J. Am. Chem. Soc. 1991, 113, 636-644. (e) Trost, B. M.; Chen, S. F. J. Am. Chem. Soc. 1986, 108, 6053-6054.

(5) (a) Trost, B. M.; Jebaratnam, D. J. Tetrahedron Lett. 1987, 28, 1611-1613. (b) Trost, B. M.; Hipskind, P. A.; Chung, J. Y. L.; Chan, C. Angew. Chem., Int. Ed. Engl. 1989, 28, 1502-1504. (c) Trost, B. M.; Tanoury, G. J.; Lautens, M.; Chan, C.; Macpherson, D. T. J. Am. Chem. Soc. 1994, 116, 4255-4267.

(6) (a) Trost, B. M.; Lee, D. C.; Rise, F. Tetrahedron Lett. 1989, 30, 651-654. (b) Trost, B. M.; Lee, D. C. J. Org. Chem. 1989, 54, 22712274. (c) Trost, B. M.; Shi, Y. J. Am. Chem. Soc. 1993, 115, 94219438. (d) Trost, B. M.; Shi, Y. J. Am. Chem. Soc. 1993, 115, 1249112509. (e) Trost, B. M.; Romero, D. L.; Rise, F. J. Am. Chem. Soc. 1994, 116, 4268-4278. (f) Trost, B. M.; Gutierrez, A. C.; Ferreira, E. M. J. Am. Chem. Soc. 2010, 132, 9206-9218.

(7) (a) Peixoto, P. A.; Severin, R.; Tseng, C.-C.; Chen, D. Y. K. Angew. Chem., Int. Ed. 2011, 50, 3013-3016. (b) Trost, B. M.; Krische, M. J. J. Am. Chem. Soc. 1996, 118, 233-234. (c) Zilke, L.; Hall, D. G. Eur. J. Org. Chem. 2012, 2012, 4153-4163. (d) Pichlmair, S.; de Lera Ruiz, M.; Basu, K.; Paquette, L. A. Tetrahedron 2006, 62, 5178-5194. (e) Trost, B. M.; Corte, J. R.; Gudiksen, M. S. Angew. Chem., Int. Ed. 1999, 38, 3662-3664. (f) Trost, B. M.; Haffner, C. D.; Jebaratnam, D. J.; Krische, M. J.; Thomas, A. P. J. Am. Chem. Soc. 1999, 121, 61836192. (g) Trost, B. M.; Li, Y. J. Am. Chem. Soc. 1996, 118, 6625-6633. (h) Trost, B. M.; Dong, L.; Schroeder, G. M. J. Am. Chem. Soc. 2005, 127, 10259-10268. (i) Yamada, H.; Aoyagi, S.; Kibayashi, C. J. Am. Chem. Soc. 1996, 118, 1054-1059. (j) Yanagita, Y.; Suto, T.; Matsuo, N.; Kurosu, Y.; Sato, T.; Chida, N. Org. Lett. 2015, 17, 1946-1949.

(8) Walker, P. R.; Campbell, C. D.; Suleman, A.; Carr, G.; Anderson, E. A. Angew. Chem., Int. Ed. 2013, 52, 9139-9143.

(9) (a) For related Diels-Alder reactions of exocyclic 2amidodienes, see: Campbell, C. D.; Greenaway, R. L.; Holton, O. T.; Walker, P. R.; Chapman, H. A.; Russell, C. A.; Carr, G.; Thomson, A. L.; Anderson, E. A. Chem. - Eur. J. 2015, 21, 12627-12639. (b) Straker, R. N.; Peng, Q.; Mekareeya, A.; Paton, R. S.; Anderson, E. A. Nat. Commun. 2016, 7, 10109.

(10) (a) See also: Trost, B. M.; Tanoury, G. J. J. Am. Chem. Soc. 1987, 109, 4753-4755. (b) Trost, B. M.; Tanoury, G. J. J. Am. Chem. Soc. 1988, 110, 1636-1638. (c) Trost, B. M.; Yanai, M.; Hoogsteen, K. J. Am. Chem. Soc. 1993, 115, 5294-5295.

(11) (a) Xu, L.-M.; Li, B.-J.; Yang, Z.; Shi, Z.-J. Chem. Soc. Rev. 2010, 39, 712-733. (b) Malacria, M.; Maestri, G. J. Org. Chem. 2013, 78, 1323-1328. (c) Catellani, M.; Motti, E.; Della Ca', N. Acc. Chem. Res. 2008, 41, 1512-1522. (d) Maestri, G.; Motti, E.; Della Ca', N.; Malacria, M.; Derat, E.; Catellani, M. J. Am. Chem. Soc. 2011, 133, 8574-8585. (e) Sehnal, P.; Taylor, R. J. K.; Fairlamb, I. J. S. Chem. Rev. 2010, 110, 824-889.

(12) Yamada, H.; Aoyagi, S.; Kibayashi, C. Tetrahedron Lett. 1996, 37, $8787-8790$.

(13) See the SI for full details of reaction optimization.

(14) (a) Le Paih, J.; Rodriguez, D. C.; Derien, S.; Dixneuf, P. H. Synlett 2000, 95-97. (b) Kaminsky, L.; Clark, D. A. Org. Lett. 2014, $16,5450-5453$.

(15) The cycloisomerization of (Z)-1b,c would likely afford the $(Z, Z)$-diene diastereomer of $\mathbf{4 b}, \mathbf{c}$; related stereoselectivity is seen in the cycloisomerization of styrenyl enynamides; see ref 8 .

(16) 6,4-Fused ring systems are formed using homologated enynamides, rather than 1,3-dienes, which is consistent with a ruthenacycle pathway. See ref 8 for further details.

(17) Chintalapudi, V.; Galvin, E. A.; Greenaway, R. L.; Anderson, E. A. Chem. Commun. 2016, 52, 693-696.

(18) See the SI for synthetic details. All deuterated compounds are fully deuterated as judged at the limits of accuracy of ${ }^{1} \mathrm{H}$ NMR spectroscopic analysis, and as such are reported as $>98 \% \mathrm{D}$. 
(19) Reactions catalyzed by $\mathrm{Pd}_{2} \mathrm{dba}_{3} \cdot \mathrm{CHCl}_{3} / \mathrm{AcOH} /$ bbeda proved capricious, particularly when run as NMR experiments, and often failed to reach completion for enynamide substrates.

(20) (a) Grushin, V. V. Chem. Rev. 1996, 96, 2011-2034. (b) Amatore, C.; Jutand, A.; Meyer, G.; Carelli, I.; Chiarotto, I. Eur. J. Inorg. Chem. 2000, 2000, 1855-1859.

(21) Experiments were run at $0.167 \mathrm{M}, 35{ }^{\circ} \mathrm{C}$ using $5 \mathrm{~mol} \% \mathrm{Pd}$ catalyst/ligand, with 1,2,4,5-tetrachloro-3-nitrobenzene as internal standard, in triplicate. See the SI for full details of NMR time course experiments.

(22) Williams, D. B. G.; Lawton, M. J. Org. Chem. 2010, 75, 83518354.

(23) In contrast to $\mathbf{1 a}$, the reactions of D-1a appear to show a retardation effect as the concentration of water increases. This may reflect an off-cycle complexation of water to the metal, which is discussed in further detail in the SI.

(24) Bedford, R. B.; Bowen, J. G.; Davidson, R. B.; Haddow, M. F.; Seymour-Julen, A. E.; Sparkes, H. A.; Webster, R. L. Angew. Chem., Int. Ed. 2015, 54, 6591-6594.

(25) (a) Bakhmutov, V. I.; Berry, J. F.; Cotton, F. A.; Ibragimov, S.; Murillo, C. A. Dalton Trans. 2005, 1989-1992. (b) Nosova, V. M.; Ustynyuk, Y. A.; Bruk, L. G.; Temkin, O. N.; Kisin, A. V.; Storozhenko, P. A. Inorg. Chem. 2011, 50, 9300-9310.

(26) This was confirmed by ${ }^{1} \mathrm{H}$ NMR spectroscopy through addition of benzaldehyde to reaction samples in $d_{8}$-toluene.

(27) We suggest that $15 \%$ product deuteration arises from the release of additional deuterium through imine/enamine tautomerization of $\mathbf{1 0}$.

(28) Stolyarov, I. P.; Demina, L. I.; Cherkashina, N. V. Russ. J. Inorg. Chem. 2011, 56, 1532-1537.

(29) (a) Fairlamb, I. J. S. Angew. Chem., Int. Ed. 2015, 54, 1041510427. (b) For a subsequent analysis of this problem, see: Bajwa, $S$. E.; Storr, T. E.; Hatcher, L. E.; Williams, T. J.; Baumann, C. G.; Whitwood, A. C.; Allan, D. R.; Teat, S. J.; Raithby, P. R.; Fairlamb, I. J. S. Chem. Sci. 2012, 3, 1656-1661. (c) Carole, W. A.; Bradley, J.; Sarwar, M.; Colacot, T. J. Org. Lett. 2015, 17, 5472-5475.

(30) Shen, R.; Chen, T.; Zhao, Y.; Qiu, R.; Zhou, Y.; Yin, S.; Wang, X.; Goto, M.; Han, L.-B. J. Am. Chem. Soc. 2011, 133, 17037-17044. (31) (a) For calculations on intermolecular ene-yne coupling, see: Henriksen, S. T.; Tanner, D.; Skrydstrup, T.; Norrby, P.-O. Chem. Eur. J. 2010, 16, 9494-9501. (b) For calculations on Pd-catalyzed 1,6enyne cycloisomerization, see: Nelson, B.; Herres-Pawlis, S.; Hiller, W.; Preut, H.; Strohmann, C.; Hiersemann, M. J. Org. Chem. 2012, 77, 4980-4995. (c) See also: Goj, L. A.; Widenhoefer, R. A. J. Am. Chem. Soc. 2001, 123, 11133-11147.

(32) (a) Frisch, M. J.; et al. Gaussian 09, Revision D.01; Gaussian, Inc.: Wallingford, CT, 2009. (b) Neese, F. WIREs Comput. Mol. Sci. 2012, 2, 73-78.

(33) Tao, J.; Perdew, J. P.; Staroverov, V. N.; Scuseria, G. E. Phys. Rev. Lett. 2003, 91, 146401.

(34) (a) TPSS is superior to GGA functionals in structure optimizations of transition metal complexes. See: Rydberg, P.; Olsen, L. J. Phys. Chem. A 2009, 113, 11949-11953. (b) Minenkov, Y.; Singstad, A.; Occhipinti, G.; Jensen, V. R. Dalton Trans. 2012, 41, 5526-5541. (c) Steinmetz, M.; Ueda, K.; Grimme, S.; Yamaguchi, J.; Kirchberg, S.; Itami, K.; Studer, A. Chem. - Asian J. 2012, 7, $1256-$ 1260. (d) Semakul, N.; Jackson, K. E.; Paton, R. S.; Rovis, T. Chem. Sci. 2017, 8, 1015-1020.

(35) (a) Schäfer, A.; Horn, H.; Ahlrichs, R. J. Chem. Phys. 1992, 97, 2571-2577. (b) Schäfer, A.; Huber, C.; Ahlrichs, R. J. Chem. Phys. 1994, 100, 5829-5835.

(36) Grimme, S. Chem. - Eur. J. 2012, 18, 9955-9964.

(37) Funes-Ardois, I.; Paton, R. S. GoodVibes v1.0.1, 2016; http:// doi.org/10.5281/zenodo.60811.

(38) (a) Grimme, S.; Antony, J.; Ehrlich, S.; Krieg, H. J. Chem. Phys. 2010, 132, 154104. (b) Grimme, S.; Ehrlich, S.; Goerigk, L. J. Comput. Chem. 2011, 32, 1456-1465. (c) Johnson, E. R.; Becke, A. D. J. Chem. Phys. 2006, 124, 174104.

(39) Marenich, A. V.; Cramer, C. J.; Truhlar, D. G. J. Phys. Chem. B 2009, 113, 6378-6396.
(40) (a) Zhao, Y.; Truhlar, D. G. Theor. Chem. Acc. 2008, 120, 215241. (b) Zhao, Y.; Truhlar, D. G. J. Phys. Chem. A 2005, 109, 56565667. (c) Riplinger, C.; Sandhoefer, B.; Hansen, A.; Neese, F. J. Chem. Phys. 2013, 139, 134101.

(41) (a) Paton, R. S.; Brown, J. M. Angew. Chem., Int. Ed. 2012, 51, 10448-10450. (b) Sanhueza, I. A.; Wagner, A. M.; Sanford, M. S.; Schoenebeck, F. Chem. Sci. 2013, 4, 2767. Further evidence for a monomeric palladium species was gained through determination of the order of reaction with respect to the catalyst, as shown in Figure 11.

(42) The reactivity of a cationic bbeda-Pd(II)H catalyst was also computed; see the SI for details.

(43) The energy and Gibbs energy profiles are very similar since the change in entropy along the intramolecular reaction coordinate is small: Peng, Q.; Paton, R. S. Acc. Chem. Res. 2016, 49, 1042-1051.

(44) (a) Rzepa, H. S. KINISOT, 2015; http://doi.org/10.5281/ zenodo.19272. (b) Paton, R. S. Kinisot.py, 2016; http://doi.org/10. 5281 /zenodo.60082.

(45) For a calculation of the KIE (2.66) for $\beta$-hydride elimination in palladium-catalyzed chain-walking, see: Hilton, M. J.; Xu, L.-P.; Norrby, P.-O.; Wu, Y.-D.; Wiest, O.; Sigman, M. S. J. Org. Chem. 2014, 79, 11841-11850.

(46) (a) Measurement of a KIE for hydropalladation of an alkyne, directed by a pyridylphosphine ligand, has been reported. This high value was ascribed to an alternative mechanism involving intramolecular protonation of an alkyne-Pd(II) complex. See: Scrivanti, A.; Beghetto, V.; Campagna, E.; Zanato, M.; Matteoli, U. Organometallics 1998, 17, 630-635. (b) For KIE measurement in allene hydropalladation, see: Zhu, C.; Yang, B.; Qiu, Y.; Bäckvall, J.-E. Chem. - Eur. J. 2016, 22, 2939-2943.

(47) Irreversible $\mathrm{C}-\mathrm{C}$ bond formation ensures carbopalladation is diastereodetermining and product selectivity may be computed applying TST assuming Curtin-Hammett-type behavior. See: Peng, Q.; Duarte, F.; Paton, R. S. Chem. Soc. Rev. 2016, 45, 6093-6107.

(48) See the SI for rationalization of the stereoselective cycloisomerizations of $\mathbf{1 h}$ and of an $(E)$-enynamide.

(49) Gómez-Gallego, M.; Sierra, M. A. Chem. Rev. 2011, 111, 48574963.

(50) Up to $11 \%$ deuterium incorporation at the enamide proton is expected across these products, arising from $11 \%$ formation of $4 \mathbf{b}$. For clarity, products $\mathbf{D}-\mathbf{5 b}$ and $\mathbf{D}-\mathbf{6} \mathbf{b}$ are represented as singly deuterated compounds.

(51) (a) Netherton, M. R.; Fu, G. C. Angew. Chem., Int. Ed. 2002, 41, 3910-3912. (b) O'Ferrall, R. A. M. J. Chem. Soc. B 1970, 785-790. (c) For a cautionary note, see: Lloyd-Jones, G. C.; Slatford, P. A. J. Am. Chem. Soc. 2004, 126, 2690-2691. (d) Bissember, A. C.; Levina, A.; Fu, G. C. J. Am. Chem. Soc. 2012, 134, 14232-14237. (e) Ogawa, R.; Shigemori, Y.; Uehara, K.; Sano, J.; Nakajima, T.; Shimizu, I. Chem. Lett. 2007, 36, 1338-1339.

(52) The reduction in turnover frequency with increasing catalyst loading provides support for off-pathway oligomerization. See: Rosner, T.; Le Bars, J.; Pfaltz, A.; Blackmond, D. G. J. Am. Chem. Soc. 2001, $123,1848-1855$

(53) Louie, J.; Paul, F.; Hartwig, J. F. Organometallics 1996, 15, 2794-2805.

(54) We believe that bidentate coordination of the substrate to the metal is required, as only 1,6- and 1,7-enynamides undergo successful cycloisomerization. This alkene-coordination effect was also noted by Trost; see ref 5c. 